\title{
Small Scale Laboratory Studies of Flow And Transport Phenomena in Pores And Fractures: Phase II
}

\section{Technical Completion Report}

DE-FG03-92ER61484

\section{by}

John L. Wilson

Department of Geoscience and Geophysical Research Center New Mexico Institute of Mining and Technology

Socorro, New Mexico, 87801

January, 1997

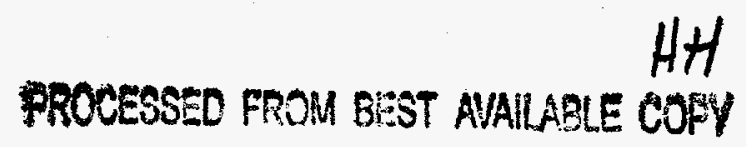

Prepared for the Subsurface Science Program Office of Health and Environmental Research U.S. Department of Energy 


\section{wipe-2n-98 05:05P V.P. for Admin. \& Finance (505)835-5659 \\ ABSTRACT

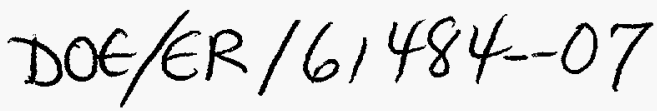

Pore level laboratory experiments using microscopy permit the in situ visualization of flow and transport phenomena, that can be recorded on film or videotape. One of the principal tools for visualization is the etched glass micromodel, which is composed of a transparent two dimensional network of three dimensional pores. The spatial scale of interest in these models extends from the individual pore, up to a nerwork of pores, perhaps with small scale heterogeneities. Micromodels are best used to help validate concepts and assumptions, and to elucidate new, previously unrecognized phenomena for further study. They are not quantitative tools, but should be used in combination with quantitative tools such as column studies or mathematical models. There are three applications: multi-phase flow, colloid transport, and bacterial transport and colonization. Specifically we've examed behavior of relevance to liquid-liquid mass transfer (solublization of capillary trapped organic liquids): liquid-gas mass transfer (in situ volatilization); mathematical models of multi-phase pressure-saturation relationships; colloid movement, attachment and detachment in the presence of fluid-fluid interfaces; clay interference with multi-phase flow; and heterogeneity effects on multi-phase flow and colloid movement.

\section{ACKNOWLEDGEMENTS}

The experiments described in this report were conducted by Robert Mace, Wendy Soll, Paul Hoffman, Peter Burck, Jiamin Wan, Teresa Nowicki, and Monty Flinsch. The work was supported by Subsurface Science Program, Department of Health and Environmental Research, Department of Ener8y. USA (Grants DE-FG04-89ER60829 and DE-FG03-92ER61484). We thank Dr. Frank Wobber of that program for his support. 


\section{DISCLAIMER}

This report was prepared as an account of work sponsored by an agency of the United States Government. Neither the United States Government nor any agency thereof, nor any of their employees, makes any wartanty, express or implied, or assumes any legal liability or responsibility for the accuracy, completeness, or usefulness of any information, apparatus, product, or process disciosed, or represents that its use would not infringe privately owned rights. Reference herein to any specific commercial product, process, or service by trade name, trademark, manufacturer, or otherwise does not necessarily constitute or imply its endorsement, recommendation, or favoring by the United States Government or any agency thereof. The views and opinions of authors expressed herein do not necessarily state or reflect those of the United States Government or any agency thereof. 


\section{DISCLAIMER}

Portions of this document may be illegible in electronic image products. Images are produced from the best available original document. 


\section{INTRODUCTION}

Investigations of transport and reactive processes in aquifers include laboratory and field experiments, and related mathematical modeling exercises. These experimental and theoretical efforts sometimes involve concepts and assumptions that have not been validated, of ten because we literally don't know where to look. Small scale laboratory experiments, equipped with an ability to actually observe behavior on the pore level using microscopy, provide an economical and easily understood scientific tool to help us validate our concepts and assumptions, and offer the propensity to discover heretofore unrecognized phenomena or behavior that could significantly effect flow and transport (Wilson, 1994).

In this project report we describe a variety of small scale experiments that emphasize the in sith visualization of phenomena as recorded on film. Video tape provides an even more graphic record, and is of special value for dynamic phenomena, but obviously cannot be shown here. The goal of visualization is to provide us, as scientists and engineers, with a better understanding of the processes that we investigate. The spatial scale of interest extends from the individual pore. up to a porous media network of pores. To illustrate the approach we focus on three easily visualized areas: multi-phase flow, colloid transport, and bacterial transport and colonization. The tool we will use for visualization is the etched glass micromodel.

Micromodels are transparent physical models of a pore space network, created by etching a pattern onto two glass plates which are then fused together (Chatzis, 1982; McKeller and Wardlaw, 1982; Wilson et al., 1990; Conrad et al., 1992; Wan and Wilson, 1994a,; Wilson, 1994, 1996). The resulting pores have complex three dimensional structure, although the network is only two dimensional.

Two photographs of a random or irregular network of pores are shown in Figure 1 . This micromodel shows pore bodies connected together by narrower pore throats. The fused glass located in between these connected channels represents the solid material in this model of a porous media. There is also glass at the top of the channels, toward the viewer, and below the channels. I often refer to these as the roof and floor of the micromodel pores. In this model the pore sizes vary from 4 microns in some of the pore throats to over 100 microns in the largest pore bodes.

The top photograph in Figure 1 is a transmitted light image, the normal way we illuminate phenomena in these models. The bottom photograph is a dark field image. Both were made with a high resolution optical microscope (Zeiss Axiophot) which was also equipped with epi-fluorescent lighting and long working distance objectives. Figure 2 shows the micromodel setup on the stage of the microscope with a video camera attached. Special objectives are needed to focus through the relatively thick glass into the pore space. The fluorescent lighting permits the use of special dyes to aid the visualization processes. The dark field image in the figure provides a quasi-three dimensional view of the pore space, showing that the pore walls in this model are relatively vertical. This lighting also shows up imperfections in the glass, which can be seen all over the model: in the pores they are beneath the floor or above the roof; they also appear within the fused zones that represent the solids. These optical imperfections have no effect on the transport issues, but must be taken into account when interpreting dark field images. 

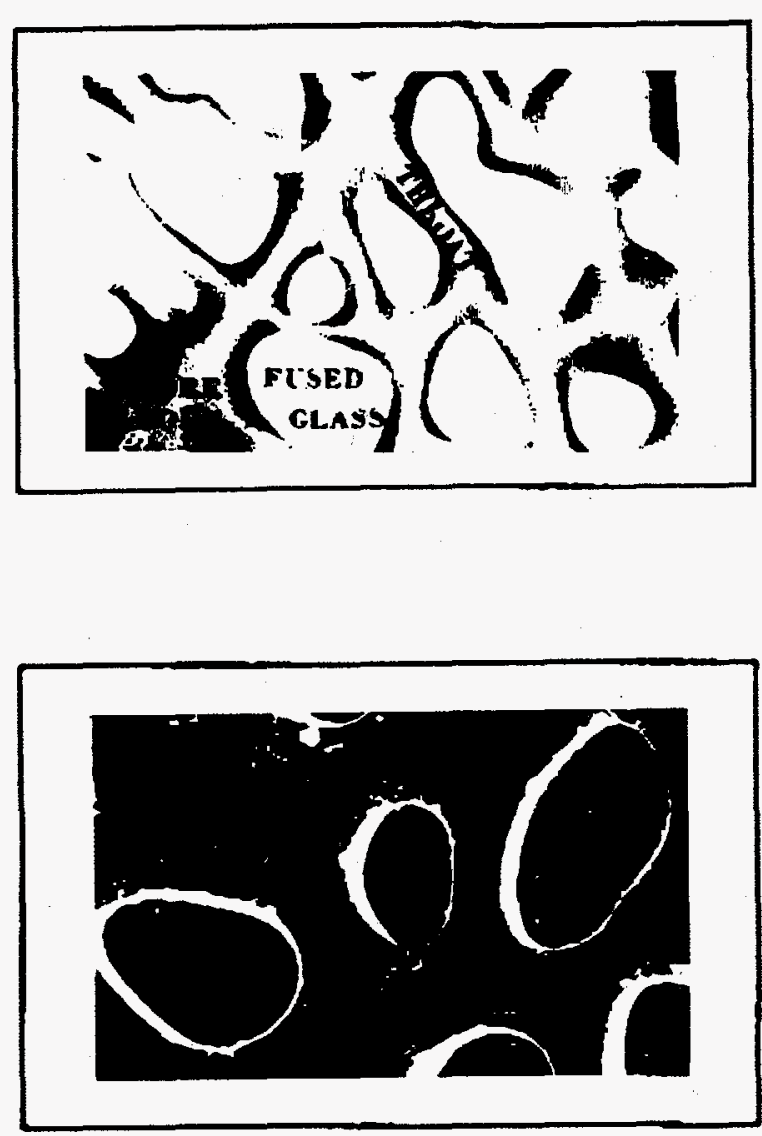

FIGIJRE 1 Transmitted light (top) and darklield (bottom) photomicrographs of a random nelwork micromodel. The pore hodies are typically 50 microns across, with some as large as 100 microns. The porc throats are of varying sizes, typically around 20 microns, but some are as small as 4 microns.

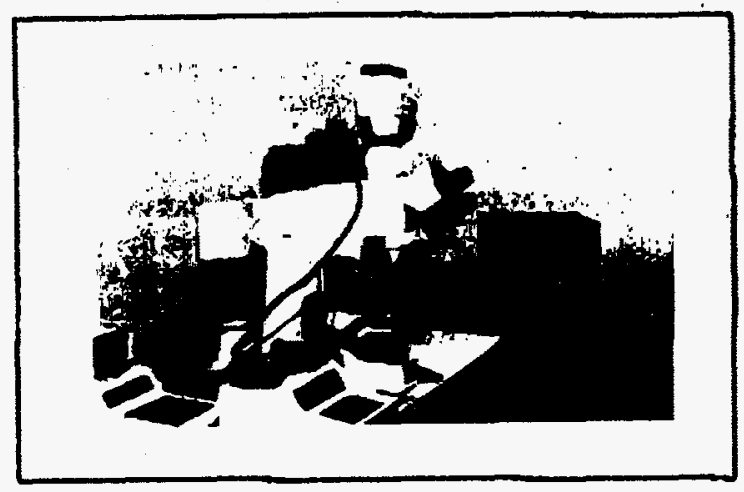

FIGURE 2 Typical micromodel setup. on the stage of a microscope.

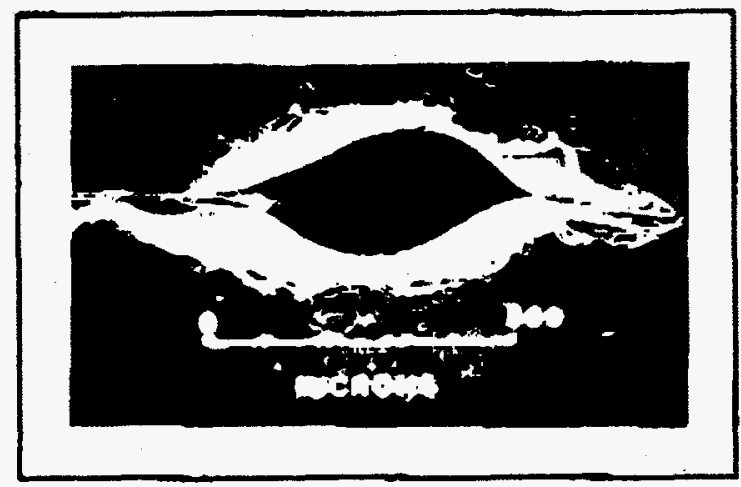

FIGURE 3 SEM view of a pore cross-section in a large micromodel that was used to study multiphase flow (Wilson et al., 1991). In this pore the walls are strongly curved. providing the pore space with prominent wodges or corners.

Depending on the manufacturing process the pore walls can be made with varying roughness and shape. Figure 3 is cross-sectional view from a much larger pore in a different micromodel. The pore has prominent wedges, or corners, where the glass plates meet. In multiphase flow the wedges play an important role, because they tend to be occupied by the wetring fluid, leaving the center of the pore occupied by a non-wetting fluid. The situation is sketched in Figure 4. These wedges are usually much less prominent, as in the model shown in Figure 1. The wedges seem to mimic behavior in natural soils, in which the wetting phase tends to remain as pendular rings at grain-to-grain contacts. However. they make it difficult for etched glass micromodels to be used for experiments simulating simple theories that require deep rectangular channels.

Phorographs of an entire model allow examination of bulk transport processes (eg. Conrad et al.. 1989; Soll et al.. 1992. 1993: Wilson, et al. 1988, 1990), while photomicrographs taken through an optical microscope permit observation of details on a pore level (eg. Wardlaw. 1982; Chaztis and Dullien. 


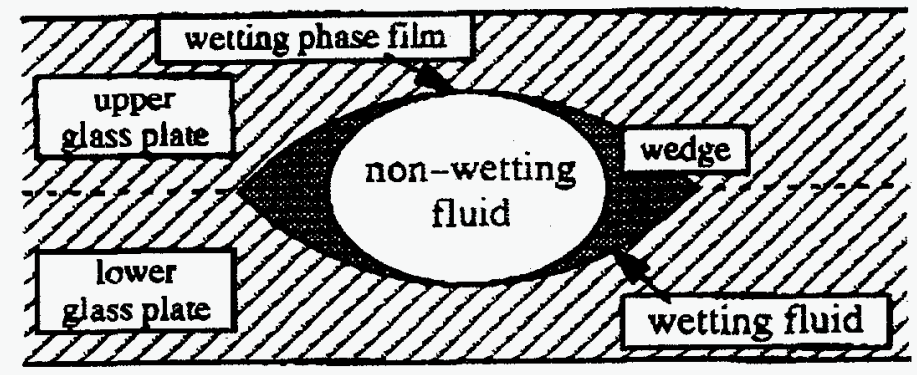

FIGURE 4 A schemaric of a pore cross-section, with the center of the pore occupied by a non-werting fluid. This pore has prominent wedges that are occupied by the wetting tluid. The wetting fluid also forms a film along the pore roof and floor, between the non-wetting fluid and the glass.

1983; Chaztis et al., 1983; Lenormand et al, 1983; Wilson et al., 1990; Conrad et al., 1992; Mace and Wilson, 1992; Wan and Wilson, 1992, 1994a; Wan et al., 1994; Wilson, 1994. 1996).

Some micromodel studies involve reactive processes and surface chemistry. These applications, discussed below, include wettability, colloid movement, and bacteria movement and colonization. The glass used for making the micromodels has $72 \% \mathrm{SiO}_{2}, 14 \% \mathrm{Na}_{2} \mathrm{O}, 3.8 \% \mathrm{CaO}$, and other trace metal oxides (Wan and Wilson, 1994a). In the presence of water the glass is covered with surface hydroxyl groups; the glass-water interface is negatively charged at neutral pH. As a consequence the surface energy of the glass is similar to that of silica solids in aquifers (eg, silica sand), and can be used to mimic its surface chemistry.

\section{METHODS}

There are various ways of manufacturing micromodels. We describe one variant of the method used in our laboratory for producing fairly large models for multiphase flow studies (Wilson et al., 1990; Conrad et al., 1992: Mace and Wilson, 1992); it is similar to that in all of the references cited above. We start with a glass mirror, stripped of its protective enamel backing to reveal a copper layer. The mirror is coated with a photosensitive resin, and a transparency of a desired pore-network pattern is placed on the coated mirror surface and exposed with ultraviolet light. The unexposed resin beneath the opaque portions of the pattern is removed with xylene. The copper beneath the pattem is removed with nitric acid, and the glass beneath the copper is etched with hydrofluoric acid (HF). A mirror-image pattern is etched on another piece of mirror glass, and the two etched halves are fused together in a muffle furnace to form a completed micromodel.

Pore-network patterns are created by a variety of means. Sometimes commercially available drafting pattern films are altered with drafting pens. Usually a computer is used to generate the pattern, which is printed on a Linotype machine. A photographer reduces each pattern to a standard size and transfers it and a mirror image to plastic transparencies. Alternatively the transparency can be printed directly by the Linotype machine. The emulsion side of each transparency is place in contact with the coated glass plates; if transparencies are laid emulsion-side up on the plate too much light leaks under the pat- 
a)

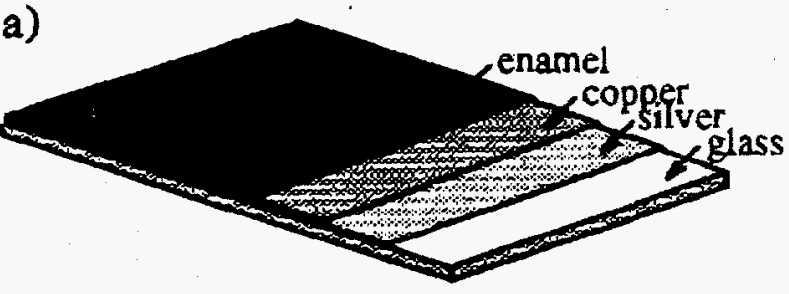

c)

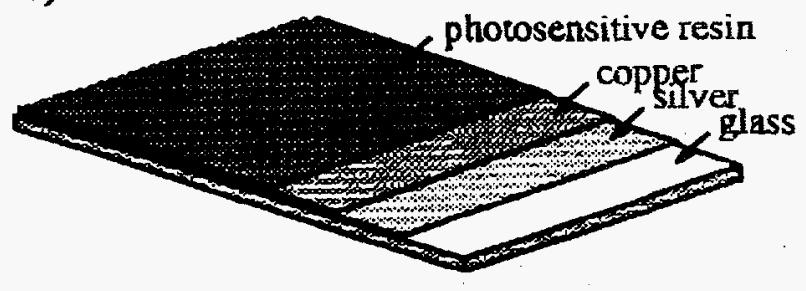

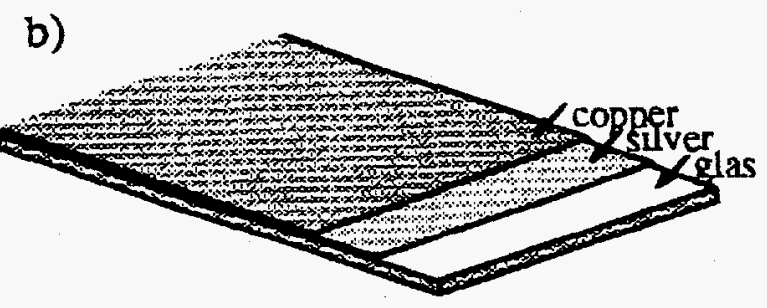

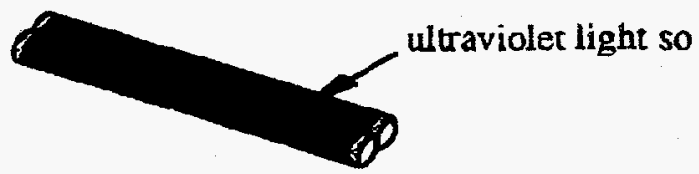

d) clear piece of glas

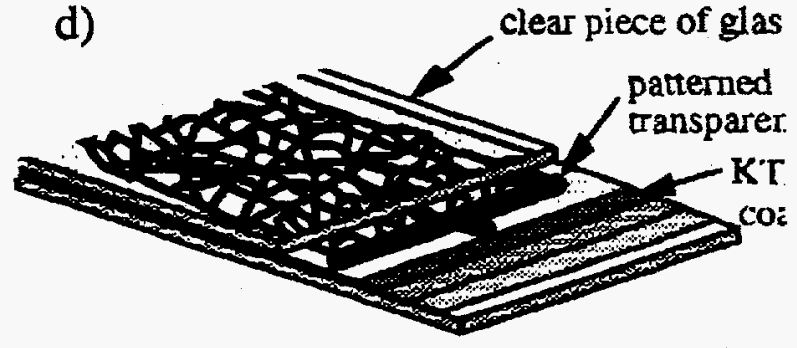

f)

e)
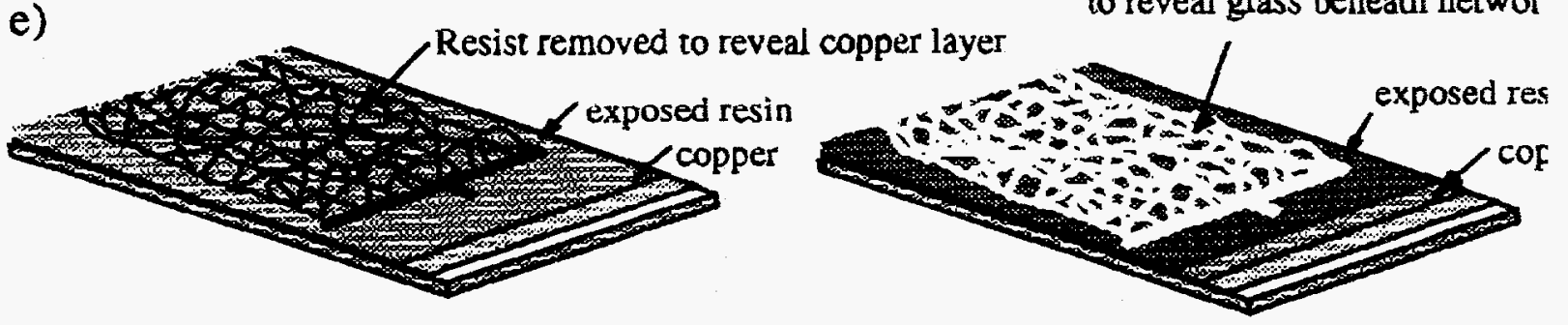

FIGURE 5 Etched glass micromodel construction (after Wilson et al.. 1990) a) Mirror consuuction. b) mirro enamel removed to reveal copper surface, c) copper surface coated with Kodak Thin Film Resist (KTFR), d. nerwork pattern exposed with UV light onto coated copper surface, e) pore nerwork pattern exposed on the coating, and f) copper and silver layers under the pore network pattem removed to reveal the underlying glass

tern during exposure to UV light. Ordinary mirrors are used for the glass (Willard mirror glass). The mirrors are manufactured by coating a piece of glass, first with a silver layer, then a copper layer, and finally a protective enamel backing (see Figure 5a). Mirrors are used in our micromodel construction as a matter of convenience: the copper layer provides a binding surface for the photosensitive resin to be applied, and the enamel backing serves to protect the copper during transport and storage. Each piece of mirror glass is prepared for coating with resin by first placing it, enamel side up, in a hot $50 \%$ by weight solution of $\mathrm{NaOH}$ to remove the protective backing. The solution is kept as hot as possible without actually boiling (approximately $90^{\circ} \mathrm{C}$ ). During the next 5-10 minutes, the integrity of the enamel 
is tested by gentle scraping with teflon tongs. When the backing scratches easily, the mirror is taken from solution and the enamel is removed from the plate by gentle rubbing with a Viton-gloved hand under a stream of hot tap water. After removing the backing the plate is rinsed with distilled water and dried in an $80^{\circ} \mathrm{C}$ oven (Figure $5 \mathrm{~b}$ ).

Kodak Thin Film Resist (KTFR), an ultraviolet-sensitive resin, is used to transfer the pore-network pattern to the mirror surface. In a darkened room, we mix 1 part KTFR by volume to 2 parts xylene. A mirror plate stripped of its protective backing is held horizontally, copper side up, and coated with a thin layer of the resist mixture. The plate is tipped in various directions to evenly distribute the resin over the copper surface in a layer of uniform thickness (see Figure $5 \mathrm{c}$ ). The plate is tilted vertically and allowed to air dry until the coating is no longer sticky to the touch (generally 20-30 minutes). Unused coated plates are stored in a dark place. After the coating is dry, the patterned transparency is placed emulsion-side down on the coated mirror surface, covered with a clear piece of glass to ensure good contact between the pattern and the surface, and placed under ultraviolet light source as illustrated in Figure 5d. Exposure times are a function of the thickness of the resin coating, the intensity of the light source, and the distance of the light source from the plate. A thick coating (an undiluted KTFR mixture) better protects the non-pore areas from HF during the etching step but requires greater exposure times than a thin coating. Thin coatings made by diluting KTFR with xylene reproduce fine details more faithfully and require smaller exposure. When the exposure is complete the plate is removed from under the UV light and the surface is sprayed with xylene. The plate is tipped back and forth for about 1 minute to wash away the undeveloped resist representing the pore-network pattern (see Figure 5e). The plate is then rinsed with warm tap water, then distilled water, after which the normal room lighting is restored. If the pattern is not visible, more xylene is applied, and the plate is rinsed again. The plate is shaken to remove excess water droplets and placed in an $80-100^{\circ} \mathrm{C}$ oven for 10 minutes, to harden the resist. The plate is removed and cooled before the next step.

The cooled model is placed in a $50 \%$ by weight solution of $\mathrm{HNO}_{3}$ for approximately 10 seconds, or until the copper and silver layers unprotected by resist (the pore-network pattern) have dissolved to reveal the underlying glass surface, as illustrated in Figure 5f. The plate is rinsed quickly with cold tap water and then with distilled water. After the plate has been dried in an $80^{\circ} \mathrm{C}$ oven, the pattern is examined under a microscope for imperfections. Small undissolved portions of the network are removed carefully with a dental tool or scriber. If necessary, the plate is re-dipped in the $\mathrm{HNO}_{3}$. then re-rinsed, to remove copper and silver left in the network after the furst acid dip. All areas of glass that are to remain unetched, such as the model edges and back, are coated with excess resist mixture and allowed to dry. The model is placed pattern-side up in a tray of concentrated HF for about 5 to 15 minutes. Longer etching times are used for models requiring deeper, wider pores. When the model is removed from solution. it is promptly rinsed in cold water, and the network is scrubbed with a wire brush to remove siliceous deposits formed during etching. The resist is removed with a razor blade. the copper and silver with HNO3, and the model is washed with detergent, rinsed with distilled water, and allowed to dry.

A mirror-image micromodel half is produced by the above methods using a mirror-image transparency. Inlet and outlet ports are drilled with a diamond drill bit in the reservoir areas of one of the plates. The two halves are aligned under a microscope, and cyanoacrylate glue is wicked in between the plates 


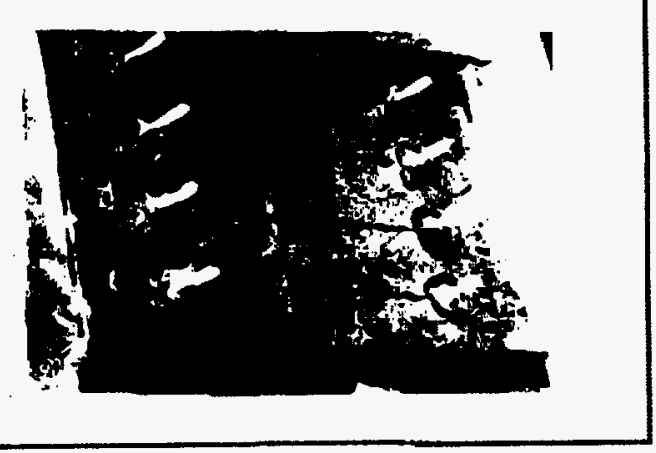

FGURE 6 A fused glass platc containing four parallel micromodel nerworks. Photomicrographs of the network are shown in Figure 1 and he network was discusscd earlier in the text. From Wan and Wilson (1994a.).

from the edges to temporarily hold them together. The model is placed in a muffle furnace and fused at $720^{\circ} \mathrm{C}$ for 15 minutes. Longer fusing times result in smoother, smaller pores; however, if a model is left too long in the furnace, some of the pores close and the network becomes disconnected.

The procedure described is one of several variants we use in the manufacturing of micromodels. It has been used to create fairly large pores, typical of the micromodels we and other's have used in the study of multiphase flow. Our standard model in this application is $10 \times 15 \mathrm{~cm}$ in area. with pores on the order of 200 to 1000 microns in size (Wilson et al.. 1990; Conrad et al., 1992; Mace and Wilson, 1992). although models as large as $15 \times 25 \mathrm{~cm}$ in area have been made with the same procedure (Wilson. 1988; Conrad et al., 1989). The maximum model dimensions are primarily limited by size of the furnace.

Smaller pores are much more difficult to fabricate. Wan and Wilson (1992: 1994a; Wan et al., 1994) substantially revised the procedure to manufacture pores as small as a few microns, with up to four tiny micromodels manufactured on a pair of glass plates, as photographed in Figure 6. The pores shown in Figure 1, and later in the colloid and bacteria experiments, are of this size. In these small models the entire network of pores, only a small portion of which is shown in Figure 1. covers an area of only 3 $\mathrm{cm}^{2}$, with a pore volume of 0.1 to $0.2 \mathrm{ml}$.

\section{MULTIPHASE FLUID FLOW}

Multiphase flow occurs in the vadose zone, where water and air are both present, and in the vicinity of the release of a non-aqueous phase liquid (NAPL). such as gasoline or tricholorethylene (TCE). The NAPL may share the pore space with both gas and water, in the vadose zone. or water alone. in the socalled saturated zone. The NAPL may be more dense than water (a DNAPL or dense NAPL) or lighter than water. In either case as it moves downward through the vadose zone it leaves behind a trail of residual. Once it reaches the vicinity of the water table it may continue to move deeper, if it is denser that water (DNAPL), or it may remain in the vicinity of the water table if it is lighter (Mercer and Cohen. 1990). In the latter case the term "water table" begins to loose its meaning. In either case, the NAPL continues 


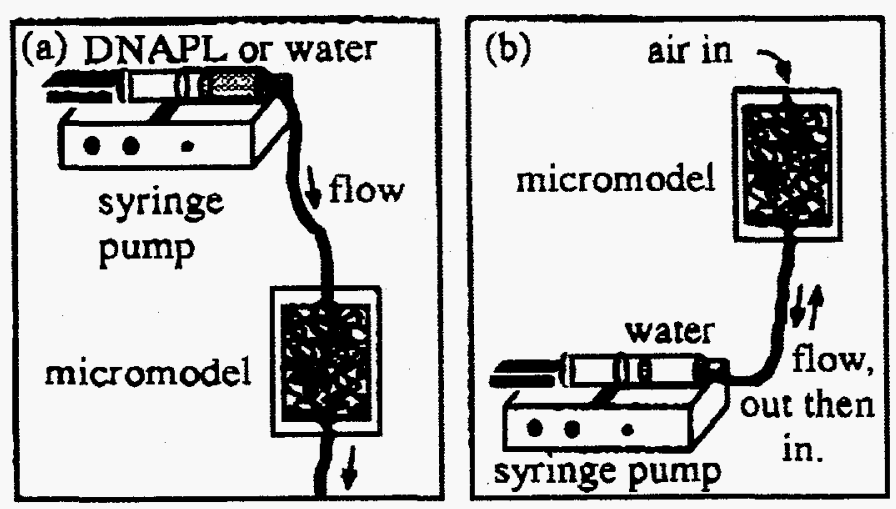

FIGURE 7 (a) Typical micromodel set-up for a DNAPL invading the water sarurated zone. and later for further downward migration of DNAPL, and replacement with water. leaving behind a residual DNAPL residual saturation. (b) Typical setup for entrapping air bubbles in a micromodel.

to leave behind a trail of residual as it moves. Micromodels can be used to examine the residual and explore various remediation alternatives.

There are three major forces acting during multiphase flow: capillary forces, viscous forces, and gravity or buoyancy forces. Capillarity is the result of the interplay of cohesive forces within each fluid phase and the adhesive forces between the solid phase and each of the fluids. The capillary force is proportional to the interfacial tension at the fluid-fluid interface and the strength of fluid wetting to the solid surface, and inversely proportional to the pore size. The vadose and saturated residuals. which are substantially different in character, are held by these capillary forces. Viscous or dynamic forces within a phase are proportional to the media permeability, the fluid phase relative permeability, and the fluid phase pressure gradient. Buoyancy is a gravitational force proportional to the density difference between เ2. - n.-. د. $\rightarrow$ 


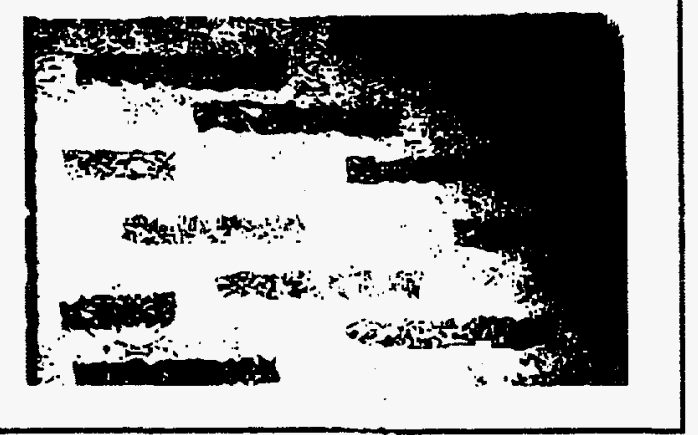

FTGURE 12 The water has swept through a heterogeneous micromodel containing a NAPl. as a non-wetting fluid. and water as a residual wetting fluid. The non-werting NAPL in the isolated coarse grained heterogeneities has been by -passed. From Wilson et al. (1990).

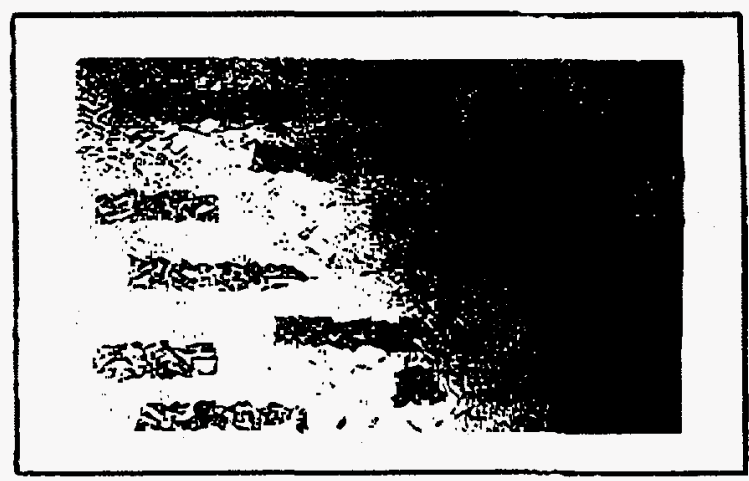

FIGURE II Water is displacing NAPL at a higher flow rate through the same heterogeneous micromddel. The flow is from the right to the left. With larger viscous forces the displacement is more efficient and less NAPL is by-passed. This pholograph was taken while the displacement was still underway. The by-passing is complete at on the right end of the model. and has not yet occurred at the left end. From Wilson et al. (1990).

in the NAPL to the organic/water interface. Since the major portion of the transfer may be occurring at the tips of these tortuous blobs, intra-blob diffusion may be the rate-limiting step (Conrad et al., 1992).

\subsection{NAPL. water, and heterogeneities.}

In related EPA sponsored work Wilson et al. (1990) explored the use of micromodels to study the effects of heterogeneities on the movement and capillary trapping of NAPL's. The top photo Figure 12 shows a $10 \times 15 \mathrm{~cm}$ micromodel with an irregular network of pores. The pores in portions of the model have been etched wider and deeper to construct zones of larger pores surrounded by a network of smaller pores. This simulates lenses of coarse porous materials (eg, coarse sand) embedded in a matrix of finer material (eg, fine sand). The model was oriented horizontally, and NAPL brought in from the side. mimicking the lateral migration of a NAPL plume along the bottom of an aquifer. Afterwards, the NAPL was displaced from the model by water, leaving behind a residual saturation. The photograph of the whole model in Figure 12 was taken at this time. The residual is dominated by the coarse lenses. In the fine material we see the typical single and multiple pore body blobs. but coarse lenses have been completely by-passed. Capillary forces are too strong. and the viscous forces in the moving water too weak, to displace the NAPL from these isolated coarser zones (Wilson et al., 1990).

This experiment was repeated at a much higher water flow rate. A photograph, taken while this was occurring, is shown in Figure 11. In contrast to the slow rate of displacement. a significant amount of NAPL has been swept fi'om the coarse lenses, even though the initial condition was essentially the same. In the swept area, on the right side, there is still some by-passed NAPL, but it is now located on the downstream end of the lenses. Sufficient viscous forces were generated to to overcome the capillary forces that held NAPL in the coarse lenses. The displacement is incomplete, because as the wetting front 


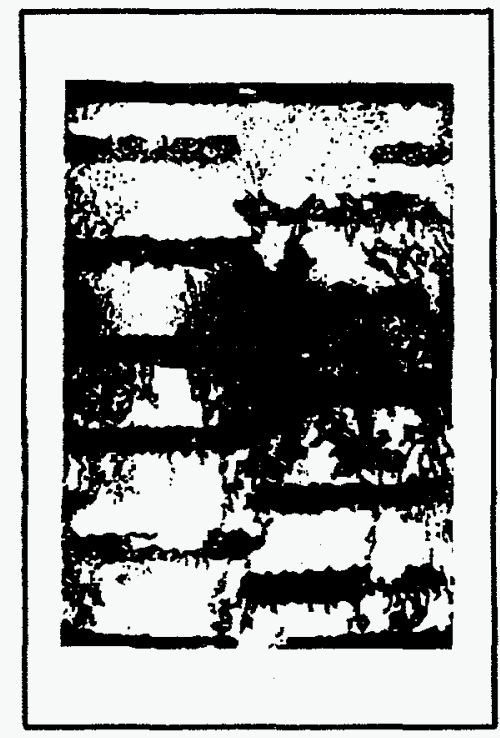

FIGURE 13 DNAPL moving downward through a water sarurated heterogeneous micromodel. From Conrad (1991).

reaches the end of a lense it closes together, and surrounds the lense. At that point the non-wetting NAPL in the lense is no longer connected with the downstream NAPL. These two photographs suggest that in heterogeneous systems the residual non-wetting phase saturation is a function of the structure of the heterogeneities, and the fluid history. Mathematical models of multiphase flow require a single number: that assumption appears to be unreasonable.

These experiments have simulated the movement of DNAPL parallel to stratigraphic bedding planes, say as it migrates along the bottom of an aquifer. What happens as it moves perpendicular to the bedding, for example. during its movement downward from the water table toward the bottom of the aquifer. Figure 13 shows the same kind of heterogeneous lenses, except for this change in geometry. The flow is downward, across the lenses, with both gravity and viscous components. As the DNAPL encounters its first coarse lense it tends to spread hoizontally, because of capillary forces. As soon as it fills a lense it begins to spill downward, but because of the gravity instabilities -DNAPL is heavier than water- this movement occurs as fingers on the scale of a few pores. When one of these fingers encounters another, deeper coarse lense, the downward migration of the DNAPL is again arrested, until the lense is filled. In essence the lenses promote horizontal spreading, here confined by the lateral boundaries of the model, and vertical fingering. The processes leads to a very inefficient displacement, with lots of water bypassed by the DNAPL. and illustrates some of the reasons why it is difficult to directly measure DNAPL's in the field, predict their behavior, or design effective remediation measures.

The concerns raised earlier about NAPL dissolution are amplified in the presence of heterogeneities. When the bypassed blob is the size of a coarse lense heterogeneity, then the blob surface area to volume ratio is incredibly small. Also the diffusion pathways become long and tortuous, with significant 
mass transfer limitations. Heterogeneity not only spreads the NAPL out in unpredictable patterns. but also slows up its remediation.

\subsection{NAPL. water. alld wethability}

In the experiments we've been discussing so far the model, and the porous media it represents, is water wet. But wetting may change for a variety of reasons, including at hazardous waste sites, the adsorption of (polar) organic compounds onto the solid (Wilson, 1989). Wei (1992) and Burck (1993) examined the effect of wetting changes on residual NAPL saturation from this perspective, while Wardlaw (1982), Buckley (1991) and many others have done the same from the point of view of petroleum reservoir engineering.

Figure 14 shows the residual NAPL in a micromodel treated with a silane compound in order to alter its surface chemistry and wettability (Wei et al., 1993). The water-NAPL advancing contact angle was $151^{\circ}$, while the receding angle was $120^{\circ}$. In the untreated model these angles were $44^{\circ}$ and $20^{\circ}$, respectively. The pore structure and size are the same as in Figures $9 \& 10$. The residual was not trapped in the characteristic locations for a non-wetting fluid. It was found in pore bodies, pore throats and, for some blobs, it has an end in both. Because of the large contact angle hysteresis of this surface, water wet conditions prevailed during the invasion of the NAPL, while intermediate wet conditions prevailed when the water re-entered to trap the NAPL. The NAPL-water interfaces in the figure clearly show evidence of both histories. In some locations, clearly water wet, we can infer that the interface was not disturbed as the water re-entered. In other locations, the contact angle shows the recent displacement of the NAPL by water. Wei (1991) and Burck (1993) also noted that the water does not seem to be interconnected through films or wedges, as it is in a water wet model. Hysteresis and lack of connection at

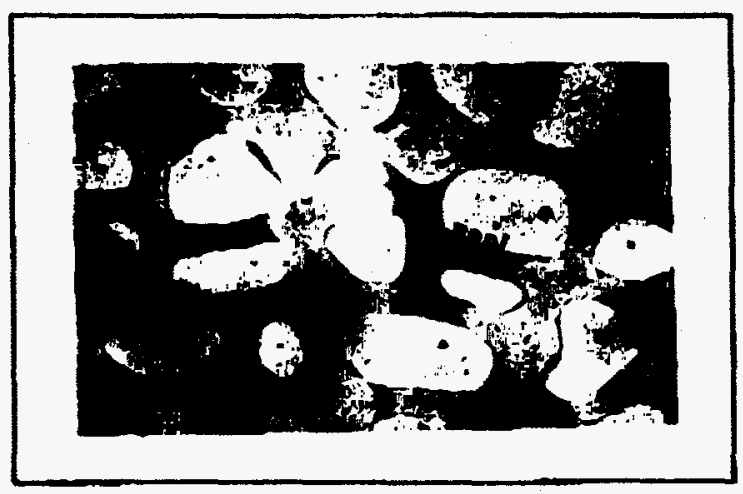

FIGURE 14 Residual non-aqueous phase sanuration in a micromodel treated with an alkoxysilane of proprietary composition. GlassGlad 18 (Huls America Petrarch, Bristol. PA.. USA). This treated surface has significant contact angle hysteresis (Wei et al., 1993). The water is light grey, and the NAPL is darker grey in this imagc. The pore bodies are up 101000 microns across. From Wei (1991). 
the pore scale make it difficult to scale pore-pressure saturation curves from column tests using only interfacial tensions and contact angles.

\subsection{NAPL, water, and air}

In the vadose zone soil scientists and hydrologists have studied three-phase gas-oil-water flow in column and sand tank experiments (eg., Schiegg, 1980; Schwille. 1988; Lenhard and Parker, 1989), but with little emphasis on pore scale phenomena. Some have simplified the system and examined two phase imbibition of NAPL's liquids into dry soils (eg., Kia, 1988). In that case the NAPL is assumed to be the wetting fluid, and the problem is essentially similar to that of water imbibition into a dry soil.

Many NAPL's have low internal cohesion and will spread, presumably forming a film between the water phase which, because of capillarity, preferentially occupies the smallest pores, and the gas phase which preferentially fills the largest pores. This film should interconnect the pockets of NAPL which even at residual saturation should be largely continuous. This is the usual assumption in mathematical models, for example, as in Lenhard and Parker (1989). The propensity to spread can be measured by the 'spreading coefficient' (Adamson, 1982; Hiemenz, 1986) :

$$
S=\sigma_{a w}-\left(\sigma_{o w}+\sigma_{a o}\right)
$$

where $S$ is the spreading coefficient, $\sigma_{a w}$ is the gas(air)-water interfacial tension (also called the surface tension), $\sigma_{o w}$ is the NAPL-water interfacial tension, and $\sigma_{a o}$ is the gas(air)-NAPL interfacial tension. The spreading coefficient measures the difference between the work of adhesion (attraction of the NAPL for the water) and cohesion (attraction of NAPL for itself). Intermediate wetting NAPL's that tend to spread as a film have a positive spreading coefficient, $S$. In this case the surface tension between the gas and water, $\sigma_{a w}$, exceeds the sum of the interfacial tensions between the NAPL and the two other fluids, $\sigma_{o w} \& \sigma_{a 0}$. Figure 16 depicts the force balance. For spreading liquids the contact angle, $\theta$, as measured through the NAPL, goes to zero. Most studies of three phase flow have focused on spreading NAPL's.

Some NAPL's have more internal cohesion, resulting in a negative spreading coefficient, $S$ (eg, halogenated hydrocarbons such as carbon tetrachioride and TCE, which are also DNAPL's). In this case the sum of the interfacial tensions between the NAPL and the two other fluids, $\sigma_{o w} \& \sigma_{d o}$, exceeds the surface tension between the gas and water, $\sigma_{a w}$ (see Figure $16, \theta>0$ ). These NAPLs will not spread as films. On a flat water surface (the gas-water interface) non-spreading liquids tend to coalesce into lenses that float on the surface (much as depicted in Figure 16), even though many of these liquids are denser than water.

Wilson (1992) used micromodels to investigate the different behavior of spreading and non-spreading NAPL's under vadose zone conditions. Using $10 \times 15 \mathrm{~cm}$ models with iriegular pores, similar to those in Figures $9 \& 10$, he simulated the scenario of a large slug of NAPL percolating vertically downward into the vadose zone (Figure 15a). Later, it was drained by air as it continued downward on its migration toward the "water table." The displacement and residual saturation left behind in the micromodel "vadose zone' was observed visually.

The experiments confirmed that a positive spreading coefficient leads to NAPL that tends to spread out as a film along the gas-water interface, as shown in Figure 17. This photomicrograph was taken after 


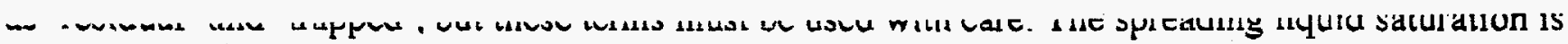
a continuous function of applied viscous and gravity forces; it can always be reduced further, albeit slowly.

A negative spreading coefficient leads to a coalescence of the NAPL into isolated pockets and tiny lenses that float at the gas-water interface, as shown in Figure 18. These pockets are not interconnected. and in many locations the gas and water are in direct contact. Negative spreading coefficients lead to isolated pockets of residual NAPL. In effect the NAPL is non-wetting as well as non-spreading, and behaves as if its effective contact angle with the water phase is significantly greater than zero.

The non-spreading experiment was designed to mimic the pore scale behavior a vadose zone sand box experiment using mineral oil. Simmons et al. (1992) concluded from these sand box experiments that non-spreading NAPL's finger due to gravity instabilities. The micromodel observations suggest that the fingering they observed is due to the smaller capillary forces associated with the mineral oil, due to its non-spreading behavior and its effective non-wetting contact angle. In their experiments the capillary forces were apparently below the threshold needed to damp out finger growth. Non-spreading liquids have a greater propensity for fingering, but do not intrinsically finger in the vadose zone. 
various pockets of oil, such as on the right side of the figure. are also generally discontinuous and not connected. From Wilson (1992).

Another potentially important observation discussed in Wilson (1992) is that mass transfer coefficients for soil venting remediation schemes may significantly depend on the sign of the spreading coefficient. Because the NAPL is almost always less wetting than water but more wetting than air, it remains in direct contact with both the air and water allowing for both solubilization into the water phase and especially volatilization into the air phase. The formation of thin NAPL films between the water and air increases the surface area of the NAPL, enhancing the propensity for inter-phase partitioning of organic components. The thin films observed in the micromodel experiments for spreading NAPL's are not of uniform thickness, and they interconnect NAPL filled pore throats. In a multi-component NAPL, mass transfer rates could be limited by the diffusion of the more volatile components to the interface, from the pore throats. The potential rate of transfer would then be distributed non-uniformly along the gas-NAPL interface, depending on the film thickness and tortuosity, and the geometry of its connection to the larger pockets of NAPL. This geometric effect could lead to local non-equilibrium mass transfer: Non-spreading NAPL's generally do not form films, but rather coalesce into isolated pockets and small lenses that float at the water-gas interface. Thus non-spreading NAPL's have a smaller contact area with the gas and water phases. Their relative mass transfer coefficients may be significantly lower, making soil venting and similar vadose zone remediation schemes less effective.

Mathematical percolation network models of multi-phase flow often assume that only one phase can occupy a given pore body or pore throat at any given time and neglect films and film flow. In micromodel experiments we commonly observe two and three phases simultaneously occupying a single pore. 


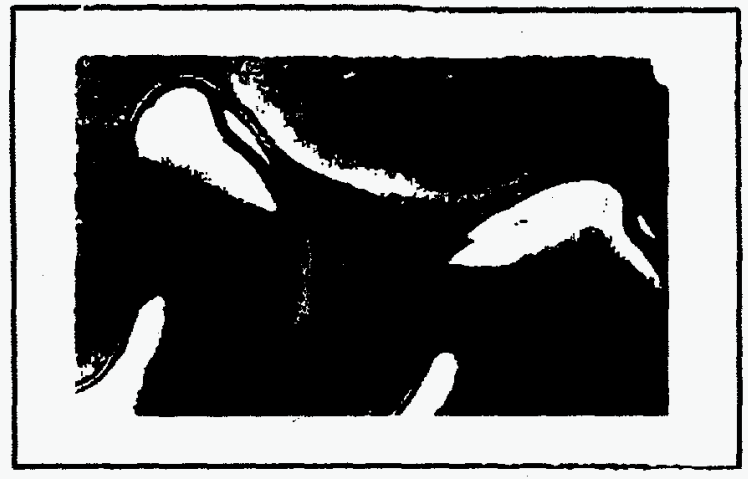

TIGURE 17 A micromodel after a spreadiug NAPL (Soltrol 130) is drained with air. Air fills the pore bodies and is interconnected through some of the pore throats. Water fills the other pore throats, some of the pore wedges, and is a werting film everywhere else. The NAPl. forms a thick film filling some pore wedges, and surrounding the air everywhere. This ubiquitous and interconnected film is particularly thick near the water filled pore throats. From Wilson (1992).

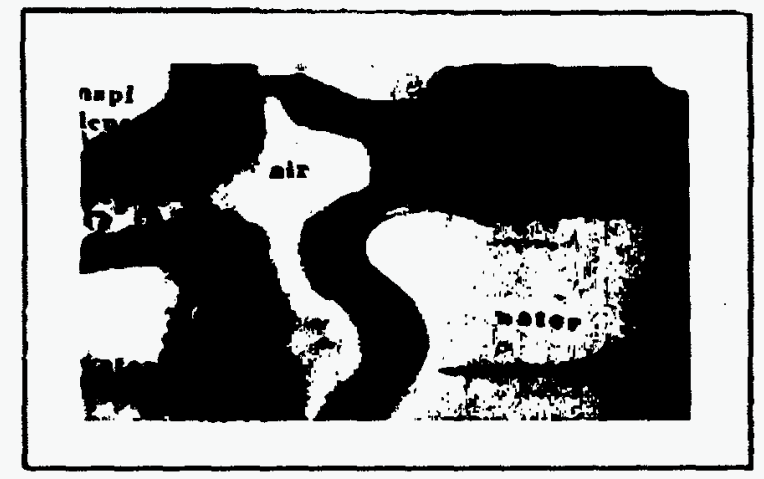

FIGURE 18 A micromodel after a non-spreading DNAPL (mineral oil) is drained with air. The DNAPL is not connected. As it leaves the photo at the botrom the air is surrounded by a film of oil. similar to that scen with the sprcading oil As the air lcaves to the left the film no longer exists. It councates somewhore in between. In this area the air-water interface is dimpled, with small lenses of mineral oil. These lenses are not interconnected. The various pockets of oil, such as on the right side of the figure. are also gencrally discontinuous and not connected. From Wilson (1992).

Another potentially important observation discussed in Wilson (1992) is that mass transfer coefficients for soil venting remediation schemes may significantly depend on the sign of the spreading coefficient. Because the NAPL is almost always less wetting than water but more wetting than air, it remains in direct contact with both the air and water allowing for both solubilization into the water phase and especially volatilization into the air phase. The formation of thin NAPL films between the water and air increases the surface area of the NAPL, enhancing the propensity for inter-phase partitioning of organic components. The thin films observed in the micromodel experiments for spreading NAPL's are not of uniform thickness, and they interconnect NAPL filled pore throats. In a multi-component NAPL, mass transfer rates could be limited by the diffusion of the more volatile components to the interface, from the pore throats. The potential rate of transfer would then be distributed non-uniformly along the gas-NAPL interface, depending on the film thickness and tortuosity, and the geometry of its connection to the larger pockets of NAPL. This geometric effect could lead to local non-equilibrium mass transfer. Non-spreading NAPL's generally do not form films, but rather coalesce into isolated pockets and small lenses that float at the water-gas interface. Thus non-spreading NAPL's have a smaller contact area with the gas and water phases. Their relative mass uansfer coefficients may be significantly lower. making soil venting and similar vadose zone remediation schemes less effective.

Marhematical percolation network models of multi-phase flow ofien assume that only one phase can occupy a given pore body or pore throat at any given time and neglect films and film flow. In micromodel experiments we commonly observe two and three phases simultaneously occupying a single pore, 

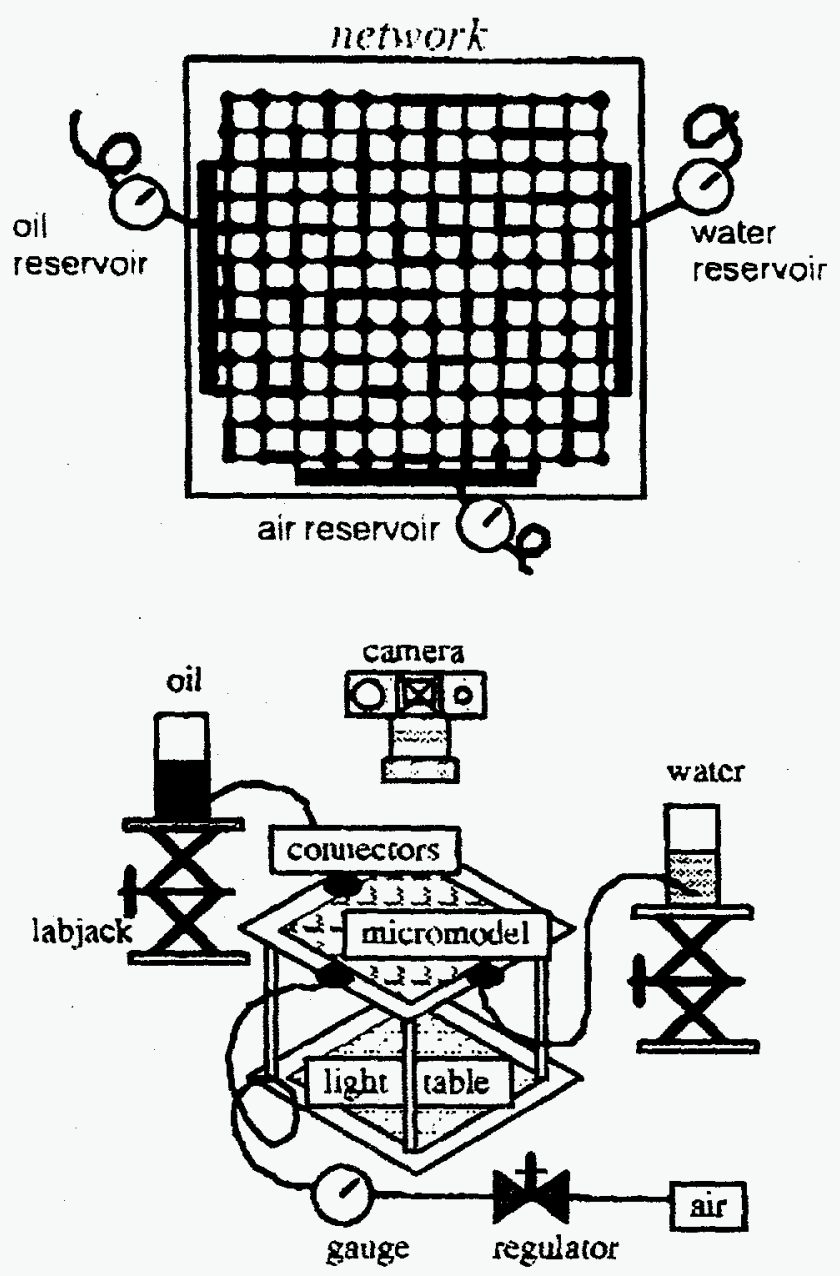

MGURT: 19 Conceprual view of capillary pressuresaturation micromodel. The actual model had many more pores. on the order of 2.500 pore bodies. After Soll et al. (1992. 1993)

and see that film or wedge flow can play an important role in the movement of NAPL's. The werting and intermediate-wetting phases remain connected through the films and wedges, which maintain a continuity for drainage or imbibition that cannot be captured using a traditional percolation network approach. Soll et al $(1992,1993)$ used a micromodel to validate a three-phase flow percolation network mathematical model (see Figure 19). They discovered that neglecting these film and wedge flow issues decreased the fidelity of the mathematical models ability to predict micromodel bulk préssure-saturation behavior.

\section{COLLOID TRANSPORT}

The retardation of toxic organic or metal contaminants depends on the degree of partitioning of these compounds berween the aqueous solution and solid-water interfaces. Solid surfaces consist of both stationary aquifer material and mobile colloidal particles (Hiemenz, 1986): silica fines, clay minerals, metal sulfides, carbonates, oxides and hydroxides, bacteria, and viruses etc. Colloidal particles have 
high surface areas per unit mass, thus posing a significant sorption potential. The fate of chemicals sorbed on colloids is determined by the fate of the colloids. In addition to enhancing the mobility of chemicals some colloids are themselves toxic or can cause disease: micro--droplets from less soluble NAPL's, and pathogenic bacteria and viruses. Finally particles are visible surrogates for dissolved contaminants. Visualization of the behavior of colloidal particles in a pore system can also promote hypotheses on the transport of dissolved species.

Our research in the area of colloid transport has focused on the role of fluid-fluid interfaces present in multi-fluid-phase porous systems, since little work has previously been done in this area. These systems occur in nature due to the presence of gas in the porous media, for example in the vadose zone. Gas can also be trapped in the saurated zone by a variety of processes: entrapment of air as the water table fluctuates, organic and biogenic activities. or gas coming out of the solution as the aqueous phase pressure drops. Fluid-fluid interfaces also occur due to the presence of non-aqueous phase liquids, as we just discussed.

\subsection{Particle atrachment}

Wan and Wilson (1992, 1994a,b) hypothesized that the gas-water interface plays a signiticant role in controlling the fate and transport of colloids through porous media. In their micromodels they studied colloid transport as water flowed through a pore network partially occupied by capillary trapped air bubbles. shown in Figure 8. The visualization work was performed in the models with fine pore bodies, less than 100 microns across, and even smaller pore throats. some of which we've already seen (Figures $1 \& 8$ ). Several different particle types were studied: polystyrene latex. clay minerals, and some bacteria. The visualization experiments were used to directly observe and compare the attachment/detachment of particles at the gas-water and the solid-water interfaces. Static gas-water interfaces were created by trapping air as residual air bubbles in the glass pore networks. as described earlier. Dynamic moving gas-water interfaces were generated by draining the model with air, displacing the aqueous phase.

Consider the pair interaction potentials for hydrophilic particles with the both the gas-water interface and the glass-water interface. For a low ionic suength solution and neutral pH, Wan and Wilson (1992, 1994a) calculated these potentials from extended DLVO theory (Hiemenz, 1986; Israelachvili, 1991), and determined that hydrophilic particles should not attach to either interface. Figure 20 shows the attachment of negarively charged, fluorescent, relatively hydrophilic (contact angle $<10^{\circ}$ ). carbloxylated polystyrene latex particles (dia. $=0.95 \mu \mathrm{m}$ ) on both the glass and the bubbles. The condition at the beginning of this experiment is shown in Figure 8. A dilute particle suspension was injected at a constant rate $(0.15 \mathrm{ml} / \mathrm{hr})$ for 30 pore volumes. Then a particle-free solution followed at the same flow rate. leaving only particles attached to the interfaces. The photomicrograph in Figure 20 was take at that time. using a combination of transmitted and epi-fluorescent light. The solution chemical conditions were designed conservatively: $1 \mathrm{mMNaNO}_{3}$ and $\mathrm{pH}$ 6.6. The hydrophilic latex particles were preferentially sorbed onto the air-water interface compared to the glass-water interface. There are very few particles sorbed onto the glass surface. Similar observations were made with montmorillorite and silica particles (Wan and Wilson, 1992, 1994a). 


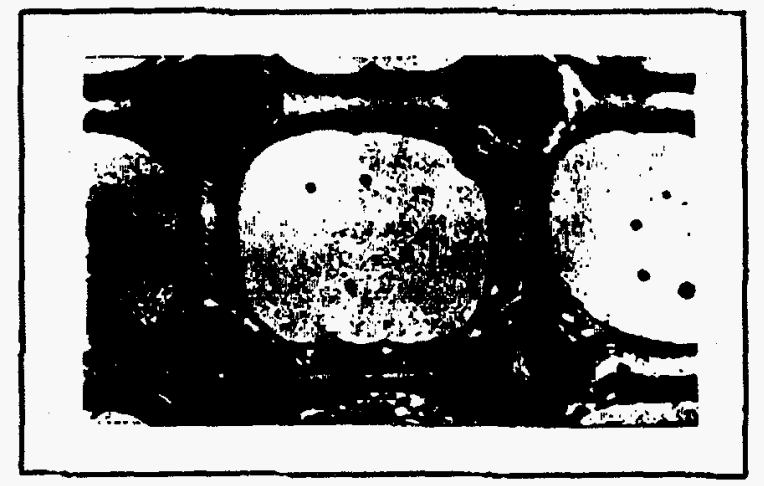

FIGURE 20 Negatively charged hydrophilic polystyrene particles attached to the surface of gas bubbles entrapped in a micromodel. From Wan and Wilson (1992, 1994a).

After varying ionic strength, particle charge, particle hydrophobicity, and other parameters, Wan and Wilson (1994a) concluded that colloidal particles preferentially attach to the gas-water interface under all conditions. The degree of attachment increases with the increasing particle surface hydrophobicity, increasing solution ionic strength, and for positively charge particles. They also observed that the attachment to the gas - water interface is essentially irreversible, and calculated that this is most likely due to the capillary free energy of particles once they make the three phase contact: particle, air and water. The mechanism by which negatively charged hydrophilic particles become sorbed to the gas-water interface is not yet clear. Wan and Wilson (1992. 1993) hypothesize that the structural or hydration interaction potential (Israelachvili, 1991) between a hydrophobic gas and a relatively hydrophilic solid is attractive in water: or it may simply be that the particles have sufficient kinetic energy to penetrate the energy barrier and reach the gas-water interface where they are then held by capillarity (Wan and Wilson. 1992. 1994a).

It is well known that there are circumstances when negatively charged, hydrophilic particles will attach to pore walls, by penetrating the energy barrier and finding the so-called primary minimum where van der Waals forces dominate. The micrograph in Figure 21 shows titanium oxide in an irregular network model (similar to that shown in Figure 1). In this case the $\mathrm{pH}=10.3$. well above the zero-point-of-charge. The oxide particles attached to the gas bubble and aggregated on its downstream side, even though there is an electrostatic repulsion between particles. We've seen similar interfacial aggregates with clay minerals (Wan and Wilson, 1994a); the latex particle aggregates visible on the gas bubbles in Figure 20 are due to capillary forces. The titanium oxide particles attached to the glass surface were mainly found in the pore throats, and other zones with high pore water velocity (see Figure 21 ). Geometrically they mimic the flow pattern. Apparently, the particle velocity and kinetic energy were high enough in these zones for the particles to penetrate the energy berrier and attach (Wan and Wilson, 1993). 
Sep'-1y-98 05:18P V.P. for Admin. \& Finance (505)835-5659

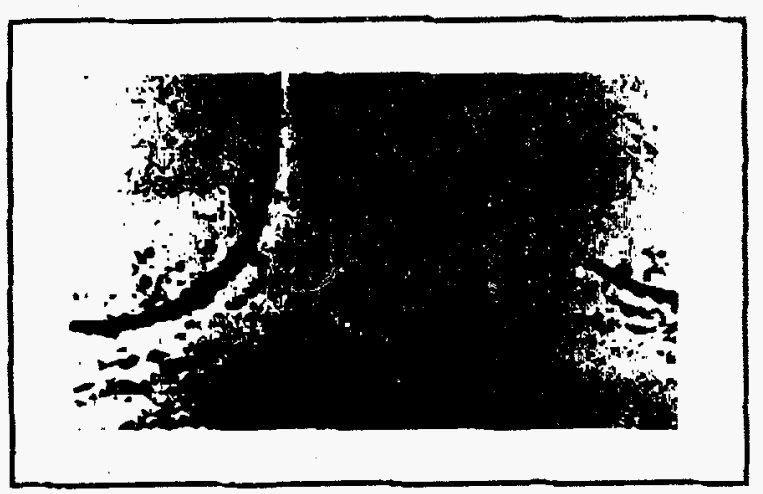

FIGLRE 21 Negatively charged hydrophilic titanium oxide ( $\mathrm{pH}=10.3$ ) attached to the glass surface and a gas bubble enrapped in a micromodel. After Wan and Wilson (1993).

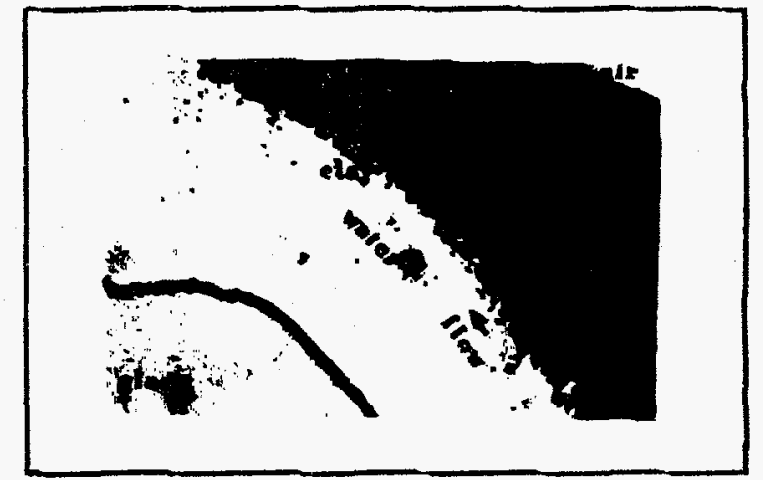

FIGURE 22 Montmorillonite clay particles in the vicinity of an air bubble occupying a pore throat. The air bubble is toward the upper right. The water is flowing along the pore wedge below it toward the upper left. Fused glass is to the lower left. From Wan and Wilson (1992).

Some relatively strange phenomena were observed in these colloid visualization experiments. One of the more curious observations was the rapid oscillation of many of the particles on the interface. Some would spin in a tight circle, others would follow a longer circuitous path (Wilson and Wan, 1994a). Even the clay interfacial aggregates showed this behavior, or variant of it: Figure 22 shows a close up along the edge of a pore throat. There are montmorillonite particles $(0.5-1.0 \mu \mathrm{m})$ in the water filled pore wedge, located near the air-water interface. On the video tape of this closeup the particles are moving to the upper left. with the water in the thickest part of the pore wedge. As you near the air-water interface the particle velocity slows down and then reverses. Particles apparently on the interface are moving in the opposite direction with the roughly the same maximum speed. Is this an indication of electrokinetics on a pore scale?

\subsection{Particle detachment with moving interface:}

Surface wettability or hydrophobicity, and surface charge vary with the different types of colloid particles. The top photomicrograph in Figure 23 shows positively charged, relatively hydrophobic (contact angle $=109^{\circ}$ ) amidine latex particles (dia. $=0.60 \mu \mathrm{m}$ ) attached to both the glass surface and the air bubble ( $1 \mathrm{mM} \mathrm{NaNO} 3$ and $\mathrm{pH}$ 6.6). The attachment of particles to the glass surface is mostly due to an attractive electrostatic force, but there is also increased attachment to the gas bubble. This may be due to a negative polarity of the bubble surface caused by reorientation of the water molecules near the gas-water interface (Wan and Wilson, 1994a), and/or the increased particle hydrophobicity.

In the next two photomicrographs we see the effect of a dynamically moving interface. In the middle the interface is moving left-to-right across the frame striping particles away from the wall as it comes into contact with them. and as it moves it is also creating local velocities high enough to detach particles. On a pore scale this is rather dramatic, and you can see streak lines of particles, acting as flow indicators, 
Sèp-1i-98 o5:18P V.P. for Admin. \& Finance (505)835-5659
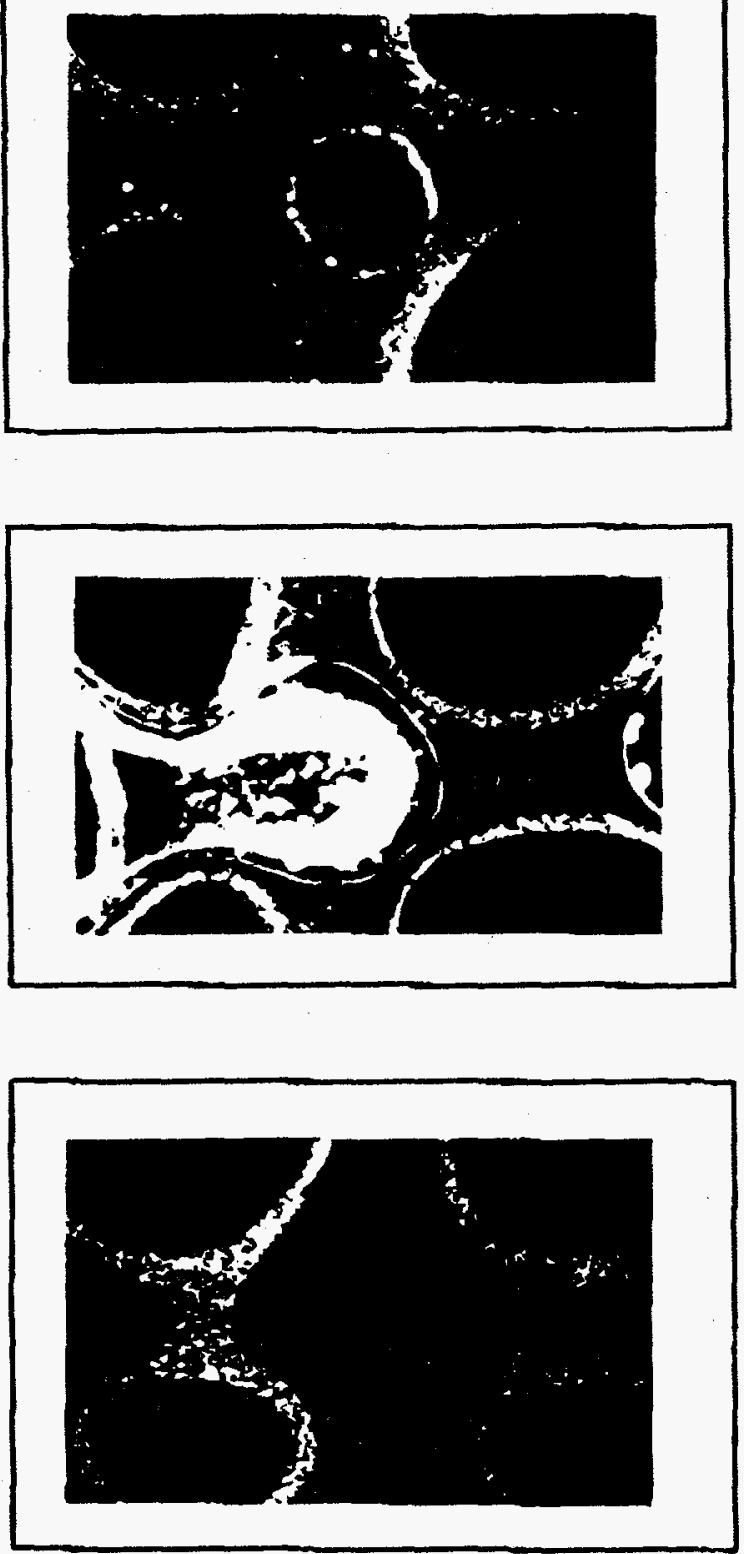

FiGURE 23 Top: positively charged hydrophohic polystyrene particles artached to the surface of glass and a gas bubble (from Wan and Wilson. 1994a). Middle: particles being swept from the surface by moving interface (trom Wan, 1993). Bortom: clcan glass surface where gas-water interface had swept by. (from Wan. 1993: Wilson. 1994). 
emphasizing this dynamic picture. The botrom micrograph shows the results. Everywhere the interface passed close to the pore walls, particles have been detached. Wan and Wilson $(1992 ; 1994 \mathrm{a})$ concluded that although stationary fluid-fluid interfaces may retard the movement of colloids, moving interfaces may enhance it. The dynamic gas-water interface phenomena may be significant in the vadose zone transport. For example. as water infiltrates into a dry soil, moving interfaces may collect particles from the pore wall and mobilize them. This process would enhance the movement of organic and inorganic colloidal matters from the soil's active-A-horizon deep into the vadose zone.

\subsection{Implications for NAPL's}

Aquifers contaminated with non-aqueous phase liquids also contain liquid-liquid interfaces. As we saw earlier the residual capillary trapped blobs are analogous to the gas bubbles. Although the interfacial force balances will be different, the gas bubble results suggest that colloids will be attracted to this interface as well. This includes clays and oxides that normally coat the pore walls. Mace and Wilson (1991) used micromodels and other tools to discover that the redeposition of these particles restructured the pore space. It may also alter interfacial properties. Both mechanisms lead to a change in behavior of the non-aqueous liquid, particularly pore pressure-saturation-permeability relationships (Mace and Wilson. 1991), and the efficacy of various aquifer remediation techniques.

\section{BACTERIAL TRANSPORT AND COLONIZATION}

Micromodels have recently been used to study the transport and colonization of microorganisms in pore spaces (Wan et al., 1994; Wan et al., 1994b; Wilson, 1996). This area of research has been stimulated by interest in the bioremediation of contaminated soils and aquifers. but may have implications for traditional concerns with on-site wastewater disposal and related public health issues.

\subsection{Transport of bacteria}

Transport of microorganisms is primarily governed by sorption or attachment to the soil and aquifer material. or by inactivation (Bales et al., 1991; Fontes et al., 1991; Bolster et al., 1998). As we saw with the inorganic colloids. many factors contribute to the attachment. Wan et al.. (1994) used micromodels to visually examine the effects of some of these factors, including cell surface hydrophobicity (Van Loosdrecht et al., 1987), and the presence of a non-wetting gas phase. The micromodels are of the same type used in the colloid studies. We'll look at results for two bacterial strains: a relatively hydrophilic Pseudomonas cepacia 3N3A $(1.3 \times 0.8 \mathrm{um})$, and a relatively hydrophobic Arthrobacter sp. S- 139 $(1.0 \times 0.8 \mathrm{\mu m})$. These two strains were isolated from groundwater systems. Wan measured the contact angles on a drained smear of bacteria, yielding $25^{\circ}$ and $77^{\circ}$. respectively, for $3 \mathrm{~N} 3 \mathrm{~A}$ and $\mathrm{S}-139$. Both bacteria strains were negatively charged under experimental conditions ( $1 \mathrm{mM} \mathrm{NaNO} 3$ and $\mathrm{pH}$ 6.6). Thirty pore volumes of a suspension of resting cells was injected into a micromodel containing water and trapped air bubbles, at a concentration of $5 \times 10^{7} \mathrm{cells} / \mathrm{ml}$. Then the cell suspension was followed by cell free water.

The top photomicrograph in Figure 24 shows the junction between an air filled pore body and a pore throat, in a hexagonal pore pattern micromodel containing bacteria $3 \mathrm{~N} 3 \mathrm{~A}$. These relatively hydrophil- 
Sep-11-98 05:19P V.P. for Admin. \& Finance (505)835-5659
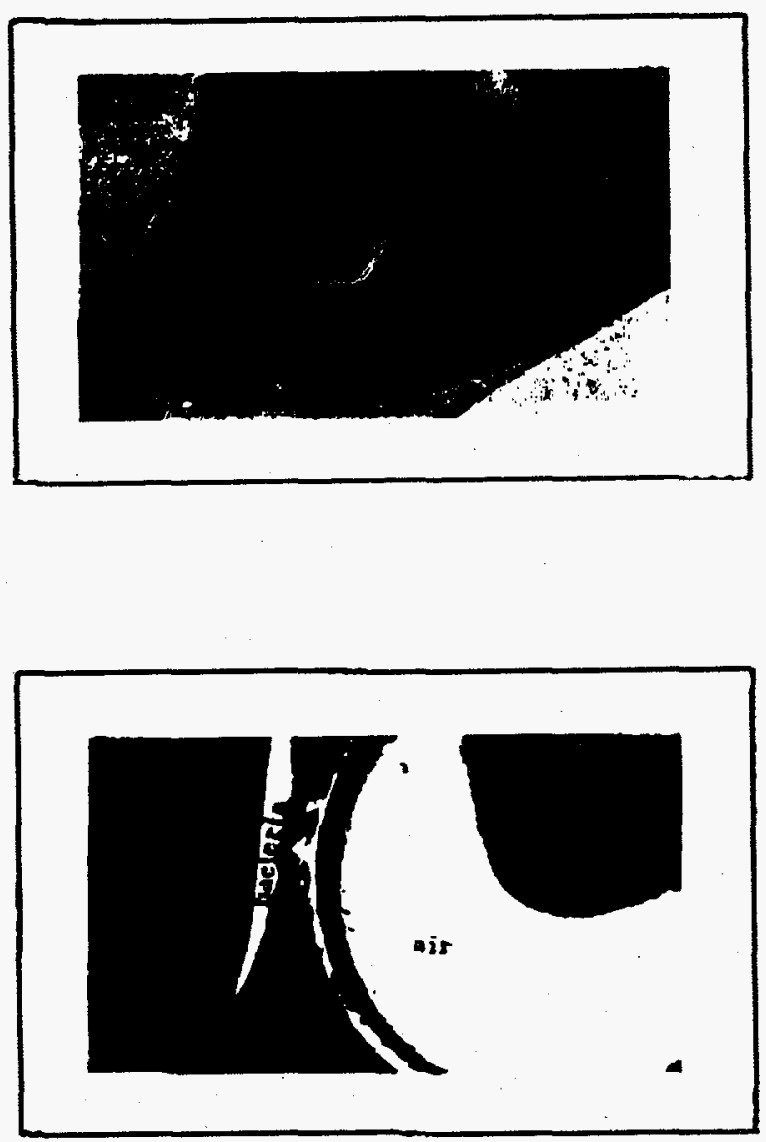

FIGIRR: 24 Top: hydrophilic bacteria are attached to the surfacc of gas bubble. Bottom: hydrophilic bacteria strained out in the pore wedge adjacent to a gas bubble.

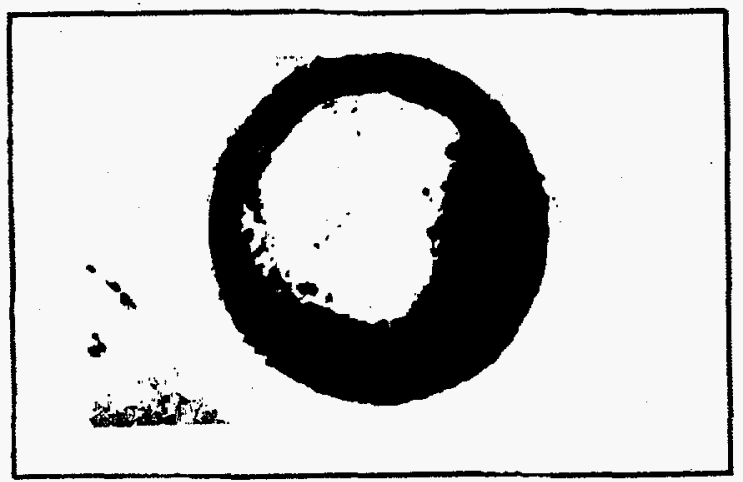

FIGURE 25 Hydrophobic bacteria attached to an air bubble and the adjacent pore walls.

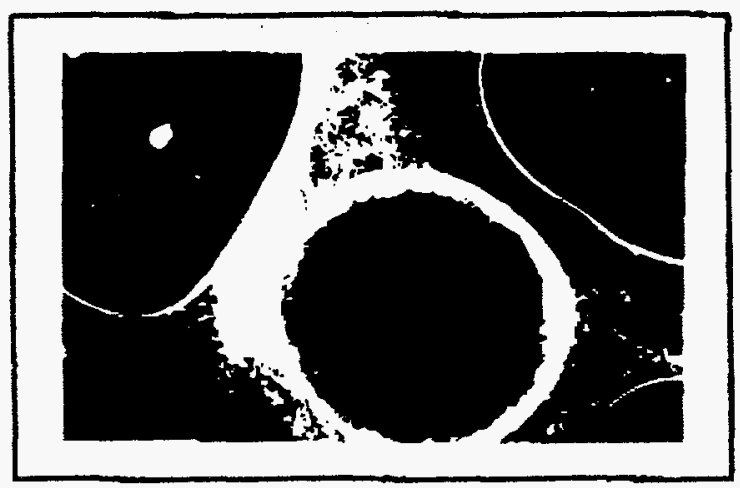

FIGURE 26 A colony of batteria in the vicinity of a isooctane blob after 48 hours of growth.

ic bacteria show up as dark grey spots on the air bubble surface. especially where it sticks into the pore throat. Almost no cells are attached to the glass surface. It appears that the bacteria may even have form aggregates. Thus the attachment behavior of this resting bacteria is similar to that observed for the negatively charged, hydrophilic, abiotic colloids, presumably for the same reasons. The bottom photomicrograph in Figure 24 is a darkfield close up of another pore, showing the narrow pore wedge. between the air bubble, and the pore wall, where the pore body joins a pore throat. This is the area of greatest flow convergence and it is obvious that a log jam of bacteria has occurred. The implication is that in the vadose zone. bacteria transport will not only be limited by attachment to the gas-water interface, but also by an increased propensity for straining in narrow water filled pore wedges. It also suggests the possibility for permeability alteration.

The relatively hydrophobic bacteria are shown in Figure 25. The large air bubble in the pore body is almost completely covered by these resting cells, and some cells have also attached to the pore walls. The preference of bacteria to attach to the air-water interface is clear even for these conditions. When 
we mobilize the bubble by increasing the water velocity. it and the bacteria attached to it left the pore, but the fluid shear stress was insufficient to detach bacteria from the pore wall (Wan et al.. 1994).

Further experiments are described in Wan et al. (1994) and summarized in Wilson (1996).

\subsection{Bacteria colonization}

Wan et al. (1994) performed another experiment, in which they entrapped residual NAPL in one of these small quadrilateral micromodels, in order to sudy the colonization of microorganisms in the vicinity of these blobs under growth conditions. Isooctane (2.2.4-trimethylpentane) was used as the NAPL. The model was fed a dilute suspension of a motile bacteria strain with intermediate hydiophobicity (Arthrobacter sp. ZALO01; contact angle $=4 \delta^{\circ}$ ). It was then cultured in sith for 48 hours using a nutrient solution, with no limitations to growth, leaving the colonies shown in Figure 26.

In this dark field photograph of a blob in a pore body the bacteria are in white. The colony favors the area around the blob, even though there are presumably no growth limitations anywhere within the pore space. Although some of the bacteria appear inside the blob (or in the water film above or below it). the bacteria clearly prefer to be in or in contact with the aqueous phase. There is a larger population density of bacteria along the water-isooctane interface This could be caused by the same kind of interfacial forces discussed earlier; perhaps bacteria that reach the interface have insufficient motility to move and break the capillary force that holds them to it. This possibility is further amplified by what happened next. The remaining cell suspension was displaced from the model. The cells attached to the blob remained behind, while most of the cells attached to the glass were removed (Wan et al., 1994).

The retention of microorganisms at fluid-fluid interfaces may be one of the major benefits of traditional donestic wastewater disposal through septic tanks and more primitive means. As long as the soil remains unsaturated the microorganisms will be much less mobile. Isolated on the air-water interface they will be subjected to osmotic and interfacial stress that may inactivate them. If the facility is overloaded and becomes saturated these sorption sites disappear, increasing the mobility of microorganisms, and increasing their propensity to reach the groundwater below.

The attraction of microorganisms to NAPL blobs suggests that they will colonize the pore space so as to enhanced solubilization and biotransformation of entrapped residual NAPL. However, if high concentrations of the NAPL or its components are toxic to the organisms, attaching to the blob surface will inactivate them, and they will have to colonize away from the blob or blob region. in order to survive.

\section{SUMMARY \& DISCUSSION}

We've introduced a variety of micromodel applications, emphasizing the visualization of flow and transport phenomena, some of which involve reactive processes. We' ve looked at the movement and capillary trapping of non-aqueous phase liquids in the saturated zone, for both water wet and intermediate wet conditions, and for both homogeneous and heterogeneous media. We've discussed the 
Sép-1i-98 o5:19P V.P. for Admin. \& Finance (505)835-5659

importance of recognizing and understanding the size. shape and disuribution of the residual as part of the study of aquifer remediation, and suggested that pore scale observations have a role in that study. We then moved upward, to the vadose zone. to examine the pore scale distribution of spreading and nonspreading non-aqueous phase liquids. The non-spreading liquids behaved almost as if the aquifer material were hydrophobic, breaking up into isolated pockets, with smaller capillary forces enhancing its tendency to finger. Adding colloids and bacteria we examined their movement in the presence of fluid-fluid interfaces. Through the microscope we saw well understood interactions with the solid surface, but some surprising things on an air-water interface. Particles that should not have attached, did attach, and were almost impossible to remove except by moving the interface itself. This suggests that fluid-fluid interfaces play a large role in the movement of colloids and microorganisms in the vadose zone, and below in the saturated zone, wherever gas bubbles or a non-aqueous phase liquid are found.

Micromodel observations should not be seen as an end in themselves. As I suggested in the introduction. they are best used to help validate concepts and assumptions, and to elucidate new, previously unrecognized phenomena for further study. They are certainly not quantitative tools (Wilson et al., 1990; Buckley. 1991). We don't know how to measure micromodel porosity, permeability or other common properties of natural porous media. Micromodels employ two-dimensional, not three-dimensional networks. Consequently we always try to run column, sand box, or other quantitative experiments in parallel, to relate quantitative data to processes we observe visually in the micromodel. For example, parallel column and micromodel experiments on capillary trapping of a non-aqueous phase liquid in the saturated zone are described by Chatzis et al. (1983), Wilson et al. (1990). Wei (1991), Conrad et al. (1992), and Mace and Wilson (1992), while parallel mathematical modeling and micromodel "experiments" on pore-pressure saturation behavior are described by Soll et al. (1992. 1993). To confirm and quantify colloid transport hypotheses suggested by their earlier micromodel observations, Wan and Wilson (1994b) ran a long series of column experiments, while Wan et al. (1994) present micromodel observations to help explain the results of bacterial transport column experiments.

One of the potential uses of miciomodels is pedagogical. Phenomena displayed on videotape are more easily assimilated by the neophyte. Its one thing to talk about capillary trapping of blobs, or particle attachment to interfaces, its another thing to actually see it. Perhaps as micromodels become more common tools in the hydrologic and environmental science and engineering research laboratories, they will be adopted for a teaching role as well.

\section{REFERENCES}

Adamson, A.W. 1982. Physical chemistry of surfaces: 4th ed. New York: Wiley.

Bales, R.C., S.R. Hinkle, T.W. Kroeger, \& K. Stocking 1991. Bacteriophage adsorption during transport through porous media: chemical perturbations and reversibility. Environ. Sci. \& Technol. 25: 2088-2095.

Bahr, J. M. 1990. Kinetically influenced terms for solute transport affected by heterogeneous and homogeneous classical reactions. Water Resour: Res. 26: 21-34.

Bales, R.C., S.R. Hinkle, T.W. Kroeger, \& K. Stocking 1991. Bacteriophage adsorption during transport through porous media: chemical perturbations and reversibility. Environ. Sci. \& Technol. 25: 2088-2095. 
Bolster. C.H., G.M. Hornberger, A.L. Mills, and J.L. Wilson, 1998, A method for calculating bacterial deposition coefficients using the fraction of bacteria recovered from laboratory columns, Environmental Science \& Technology, in press.

Buckley. J. 1991. Multiphase displacements in micromodels. Interfacial phenomena in petroleum recovery. N.R. Morrow, Ed.: 157-189. New York: Marcel Dekker:

Chatzis. I. 1982. Photofabrication technique of nwo dimensional glass micromodels. PRRC Rpt. 82-12. Socorto, New Mexico: New Mexico Institute of Mining and Technology.

Chatzis, I. \& F. A. L. Dullien 1983. Dynamic immiscible displacement mechanisms in pore doublets: theory versus experiment. Jour. of Colloid and Interface Sci. 91: 199-2222.

Chatzis, I. N. R. Morrow, \& H. T. Lim 1983. Magnitude and detailed structure of residual oil saturation. SPE.Jour. 23: 311-325.

Conrad, S. H 1990. Laboratory experiments on the multiphase flow of organic liquids in the vadose and saturated zones. Ph.D. Thesis. Socorro, New Mexico :Geoscience Department, New Mexico Inst. of Mining and Technology.

Conrad, S. H., J. L. Wilson, W. R. Mason, \& W. Peplinski. 1989. Observing the transport and fate of petroleum hydrocarbons in soils and in ground water using flow visualization techniques. Proc. sym. on environ. concerns in the petroleum industry. Palm Springs, Ca.: AAPG.

Conrad, S.H., J.L. Wilson. W.R. Mason, \& W. Peplinski 1992. Visualization of residual organic liquid trapped in aquifers Water Resour. Res. 28: 467-478.

Davis, J.A. \& S.C. Jones 1968. Displacement mechanisms of miscellar solutions. Jour. of Petro. Tech. Dec.: 1414-1428.

Fontes, D.E., A.L. Mills, G.M. Hornberger, \& J.A. Herman 1991. Physical and chemical factors influencing transport of microorganisms through porous media. Appl. and Environ. Microbiol. 57: 2473-248I.

Gvirtzman, H., M. Magaritz, E. Klein, \& A. Nader 1987. A scanning electron microscopy study of water in soil. Transp: In Porous Media. 2: 83-93.

Hiemenz, P.C. 1986. Principles of colloid and surface chemistry. 2nd ed., New York: Marcel Dekker.

Israelachvili, J.N. 1991. Intermolecular and surface forces. 2nd ed.. Academic: New York.

Kia, S.F. 1988. Modeling of the retention of organic contaminants in porous media of uniform spherical particles. Water Res. 22: 1301-1309.

Lenhard, R. J. \& J. C. Parke. 1989. A model for hysteretic constitutive relations governing multiphase flow, 3. refinements and numerical simulations. Water Resour. Res. 25: 1727-36.

Lenormand, R.. C. Zarcone and A. Saar 1983. Mechanisms of the displacement of one fluid by another in a network of capillary ducts. Jour. of Fluid Mech. 135: 337-353.

McKellar, M. \& N.C. Wardlaw 1982. A method of viewing water and oil distribution in nativestate and restored-state reservoir core. AAPG Bul. 72: 765-71.

Mace, R. \& J.L. Wilson 1992. Clay and immiscible organic liquids: greater capillary trapping of the organic phase. Chap. 17, Transport and remediation of subsurface contaminants: colloid, interfacial, and surfactant phenomena. D.A. Sabatini \& R.C. Knox, Eds.: 205-216. Washington, D.C.:American Chemical Society.

Mattax, C.C. \& J.R. Kyte 1961. Did you ever see a water flood? The Oil and Gas Jour. 59: 115-128.

Mercer, J.W. \& R.M. Cohen 1990. A review of immiscible fluids in the subsurface: Properties, models, characterization and remediation. Jour. of Contamincunt Hydrology 6: 107-163.

Miller, C. T., M. M. Poirier-McNeill, \& A. S. Mayer 1990. Dissolution of trapped nonaqueous phase liquids: mass tuansfer characteristics. Water Resolur. Res. 26: 2783-2796.

Powers, S. E. C.O. Louriero, L. M. Abriola, \& W. J. Weber 1991. Theoretical study of the significance of non-equilibrium dissolution of non-aqueous phase liquids in subsurface systems Water Resour. Res. 27: 463-478. 
Sép-11-98 05:20P V.P. for Admin. \& Finance (505)835-5659

Schiegg, H.O. 1980. Fundamentals. setups, and results of laboratory experiments on oil propagation in aqueifers. VAW-Mitteilung no. 43, Zurich.: Versuchsanstalt fur Wasserbau., Hydrologie und Glaziologie, ETH.

Schwille. F. 1988. Dense chlorinated solvents in porous and fractured media. Chelsea. Michigan: Lewis.

Soll, W., M. Celia, \& J.L. Wilson 1992. Quantitative comparison of computational and experimental methods for three phase immiscible transport. Subsurface contamination by immiscible fluids. U. Weyer, Ed.: 229-238. Rotterdam: Balkema.

Soll, W., M.Celia, \& I.L. Wilson 1993. Micromodel studies for three-fluid porous media systems: pore-scale processes and capillary pressure-saturation relationships. Water Resour. Res. 29: 2963-2974.

Simmons, S.. J. McBride, J. Cary \& R.J. Lenhard. 1992. Organic liquid infiltration into unsaturated porous media. Subsurface contamination by immiscible fluids. U. Weyer, Ed.: 213-220. Rotterdam: Balkema.

Van Loosdrecht, M.C.M., J. Lyklema, W. Norde, G. Schraa \& A.J.B. Zehnder 1987. Electrophoretic mobility and hydrophobicity as a measure to predict the initial steps of bacterial adhesion. Appl. and Environ. Microbiol. 53: 1898-1901.

Wan, J. 1993. The role of the gas-water interface on the transport of colloids and bacteria in porouts media. Ph.D. Thesis. Socorro, New Mexico :Geoscience Department, New Mexico Inst. of Mining and Technology.

Wan, J. \& J.L. Wilson 1992. Visualization of colloid transport during single and two-fluid phase flow in porous media. Chap. 5, Transport and remediation of subsurface contaminants: colloid. interfacial, and surfactant phenomena, D.A. Sabatini \& R.C. Knox, Eds.: 55-70. Washington. D.C.:American Chemical Society.

Wan, J. \& J.L. Wilson 1993. Colloid transport and the gas-water interface in porous media. Chap. 55, Manipulation of grolundwater colloids for environmental restoration. J.F. McCarthy and F.J. Wobber, Eds.: 335-339. Washington, D.C.. Lewis.

Wan, J. \& J.L. Wilson 1994a. Visualization of the role of the gas-water interface on the fate and uransport of colloids in porous media. Water Resour. Res., 30(1): 11-23.

Wan, J. \& J.L. Wilson. 1994b. Colloid transport in unsaturated porous media. Water Resour. Res.. 30(4): $857-864$.

Wan, J., J.L. Wilson, \& T.L.Kieft 1994. The gas-water interface as an influence on the transport of microorganisms through unsaturated porous media. Appl. and Environ. Microbiol., 60(2): 509-516.

Wardlaw, N.C. 1982. The effect of geometry, wettability, viscosity, and interfacial tension on trapping in single pore throat pairs. Jour. of Canadian Petro. Tech. 21:21-27.

Wei, M. 1991. Wetting and non-aqueous phase liquid saturations in homogeneous porous media. M.S. Thesis. Socorro, New Mexico :Hydrology Program. New Mexico Inst. of Mining and Technology.

Wei, M., R. Bowman, J.L. Wilson \& N. Morrow 1993. Wetting properties and stability of silane treated glass exposed to water, air and oil. Jotur. of Colloid and Interfacte Sci. 157: 154-159.

Wilson, J.L. 1988. Wetting as a factor in the measurement of floating non-aqueous phase liquids. EOS 69: 1212 .

Wilson, J.L. 1989. The Role of Wetting in Environmental Problems. Proc. of Conference on Findamental Research Needs in Envirommental Engineering: 16-22. Washington, DC.: Assoc. Environ. Engr. Professors.

Wilson, J.L. 1992. Pore scale behavior of spreading and non-spreading organic liquids in the vadose zone. Subsurface contamination by immiscible fluids. U. Weye, Ed.: 107-114. Rotterdam: Balkema. 
Wilson, J.L., 1994, Visualization of flow and transport at the pore level. Transport and Reactive Processes in Aquifers, T.H. Dracos \& F. Stauffer, Eds., Balkema, Rotterdam, 19-36.

Wilson, J.L.. 1996, Visualization experiments at the pore scale, Groundwater and Subsurface Remediation, H. Kobus, B. Barczewski, and H.-P. Koschitzky, Eds., Springer Verlag, 89-98.

Wilson, J.L., S. H. Conrad, E. Hagan, W.R. Mason, W. Peplinski, \& E. Hagan 1990. Laboratory investigation of residucl liquid organics. Rpt. CR-813571, Ada, Oklahoma:U.S. Environmental Protection Agency.

Wilson, J.L. S.H. Conrad, E. Hagan, W. Mason, \& W. Peplinski 1988. The pore level spatial distribution and saturation of organic liquids in porous media. Proc. of petroleum hydrocarbons and organic chemicals in ground water. 107-133. National Water Well Association: Dublin, Ohio. 


\section{APPENDIX I \\ Graduate Students Trained and Degrees Granted}

Six graduate students have worked on this project: an engineer. a geochemist, a geophysicist. a geologist, a biologist, and a mathematician, illustrating the multi-disciplinary nature of the hydrology program and our research. Dr. Wan is currently continuing the colloid work begun in this project as a research scientist at Lawrence Berekely Labs. Among other things she has continued to improved the micromodel method. Dr. Soll is currently a scientist with Los Alamos National Laboratory where she is continuing her work on the pore scale behavior of multiple fluid phases, primarily using Lattice Bolzman mathematical modeling techniques. Dr. Mace (Mace, M.S. 1990) went on to the University of Texas to complete his Ph.D. He is now with the Texas Bureau of Economic Geology in Austin. Burck and Nowicki are employed by hydrologic consulting firms. Flinsch works for an internet company. In addition, an undergraduate Paul Hofmann worked for three years on the experiments. He continued on for an MS, taking only a year to complete it on an unrelated topic (modeling), then went to work for DOE's Oak Ridge Operations Office. A high school student, now a med student at UC Berkeley, worked on micromodels studies of blob mobilization and dissolution, for science fair projects. He won second place in the International Science Fair for his dissolution work on benzene.

Mace, R.E., 1990, The Effect of the Fine Fraction on the Residual Trapping of Non-Aqueous Organic Liquids in Unconsolidated Porous Media in the Saturated Zone, MS Independent Study. Open File Rpt. H90-6, Hydrology Program. New Mexico Inst. of Tech., Socorro, New Mexico.

Soll,W.E., 1991, Development of a Pore-Scale Model for Simulating Two and Three Phase Capillary Pressure-Saturation Relationships, Ph.D. Thesis, Dept. of Civil Engr., Mass. Inst. of Tech., Cambridge, Massachusetts.

Peter W. Burck, 1993, The Influence of Wettability on Scaling the Capillary Pressure Relationship, Hydrology Program, Department of Geoscience, New Mexico Tech.

Wan. J., 1993, The Role of the Gas-Water Interface on the Transport of Colloids and Bacteria in Porous Media, Ph.D. Thesis, Dept. of Geoscience. New Mexico Inst. of Tech., Socorro, New Mexico.

Nowicki, T., 1995, Visualization of Bacteria in a Contaminant Plume, Hydrology M.S. Thesis, Dept. of Geoscience, New Mexico Inst. of Tech,, Socorro. New Mexico.

Flinsch, M., 1998, Estimation of Bacteria Hydrophobicity: An Improved Method, Hydrology M.S. Thesis. Dept. of Geoscience, New Mexico Inst. of Tech., Socorro, New Mexico. 


\section{APPENDIX II \\ Publications and Presentations}

The following bibliography lists project outpus (exclusive of theses) in chronological order, since the inception of Phase I. We have seven manuscripts published in refereed journals. Most of these papers are in Water Resources Research. We have eight papers published in books or proceedings. Six of these papers cover our early and somewhat inconclusive work. The last two are review papers. describing the visualization technique and its various applications. We've given over 20 papers to scientific meetings, including several Subsurface Science Program gatherings. Primarily through the medium of the Darcy Lecture Tour we have also given over thirty seminars and lectures at universities around the U.S. and Australia describing project related work. Six theses have been completed as part of this work (see Appendix I).

The number on the right designates the DOE report/document number we assigned to each publication. The missing numbers were assigned to progress reports and other documents prepared for DOE. These reports are not listed here.

This report was updated in July, 1998.

a) Project relaced Honors

J. Wilson was invited to give the 1992 Darcy Lecture Tour, sponsored by the National Ground-Water Association. on visualization of flow and transpon.

A. Bagri. won second place. Physics Division. International Science Fair. 1993.

J. Wilson was invited to give the 1993 Fred Holmsley Moore Distinguished Lecturer. University of Virginia. on the project bacteria transport wark.

J. Wan won the 1994 Lewis Publishers-Fnvironmental Chemistry Division Graduate Student Paper Award, from the American Chemical Society.

J. Wan won the 1994 "Best Dissertation Award" in Environmental and Biological Sciences. Liniversities Council on Water Resources.

J. Wilson was Elected Fellow of the Amcrican Geophysical Union. 1994: his visualization work sponsored by the Subsurface Science Program was cited.

J. Wilson was presented the 1996 O.E. Meinzer Award by the Geological Sociery of America: his visualization work sponsared by the Subsurface Science Program was cited.

J. Wilson was presented the 1998 New Mexico Institute of Mining and Technology Research Award: : his visualization work sponsored by the Subsurface Science Program was cited by outside reviewers.

b) Papers in refereed journals

Conrad. S.H. J.L. Wilson. W.R. Mason and W.J.Peplinski. "Visualization of Residual Organic Liquid Trapped in Aquifers." Water Resources Reseanch. Vol. 28. No. 1. pp.

DOE/ER/60829-03 467-478. 1992. 
Soll. W.. M.Celia. and J.L. Wilson. "Experimental Procedure for Direct Observation and Quantification of Three-Fluid Displacement Processes in Porous Media." Water Resources Research. Vol. 29. No. 9. pp. 2963-2974. Seplember. 1993.

Wan. J, and J.L. Wilson. "Visualization of the Role of the Gas-Water Interface on the Fate and Transport of Colloids in Porous Media." Water Resources Research. Vol. 30. No. 1.pp. 11-23. 1994.

Wan, J. and J.L. Wilson, "Colloid Transport in Unsaturated Porous Media," Water Resources Besearch, Vol. 30, No. 4, pp. 857-864, 1994.

Wan. J. J.L. Wilson. and T.L.Kieft. "The Gas-Water Interface as an Influence on the Transpor of Microorganisms Through Unsaturated Porous Media." Applied and Environmental Microbiology, Vol, 60. No. 2. pp. 509-516. 1994.

Bolster. C.H., G.M. Hornberger. A.L. Mills. and J.L. Wilson. "A Method for Calculating Bacterial Deposition Coefficients Using the Fraction of Bacteria Recovered from Laboratory Columns." Environmental Science \&echoology. in press. 1998.

DeFlaun, M.F., C.J. Murray, W. Holben. T. Schreibe. A. Mills, T. Gins, T., Griffin. E. Majer, and J.L. Wilson. 'Preliminary Observations on Bacterial Transpor in a Coastal Plain Aquifer." FEMS Microbiology Reviews. Vol. 20. pp. 473-487, 1997.

c) Papers published in reviewed books and conference proceedings

Wan, J. and J.L. Wilson. "Colloid Transport and the Gas-Water Interface in Porous Media." Chap. 5. Transport and Remediation of Subsuface Contaminants: Colloid. Interfacial, and Surfactanc Phenomena. D.A. Sabatini and R.C. Knox . Eds., Arnerican Chernical Society. pp.55-70. 1992.

Mace. R. and J.L. Wilson, "Clay and Immiscible Organic Liquids," Chap. 17. Iransport and Remediation of Subsurface Contaminants: Colloid Interfacial and Surfactenc Phenomena. D.A. Sabatini and R.C. Knox , Eds.. American Chemical Society. pp.205-216. 1992.

Soll. W.. M. Celia, and J.L. Wilson, "Quantitative Comparison of Computational and Experimental Methods for Three Phase Immiscible Transport." Subsurface ContamiDaxion by Immixcible Fluids. U. Weyer. Ed., Balkema, Rotterdam. pp.107-114, 1992.

Wilson. J.L.. "Porc Scale Behavior of Spreading and Non-spreading Organic Liquids in the Vadose 7.one." Subsurface Contamination by Immiscible Fluids. U. Weyer. Ed.. Halkema. Rotterdam pp. 229-238, 1992.

Wan. J. and J.L. Wilson. "New Findings on Particle Transport within the Vadose Zone: The Role of the Gas-Water Interface." in American Geophysical Union.12th Annual Hydrology Days. II. Morel-Seytoux. Fd.. Hydrology Days Publications. Atherton, Ca.. pp. 402-419. 1992.

Wan. J. and J.L. Wilson. "Visualization of Colloid Transport During Single and TwoFluid Phase Flow in Porous Medis." in Manipulation of Groundwater Colloids for Environmeplal Restoration. J.F. McCarthy and F.J.Wobber, Fds., Lewis Publishers. Boca Raton. FI.. pp. 335-339. 1993.

Wiison. J.L., "Visualization of Flow and Transport at the Pore Level" Iransport and Reacrive Processes in Aquifers. T.H. Dracos \& F. Stauffer. Eds.. Balkena. Rotterdam. pp. 19-36. 1994.

Wilson. J.L.. "Visualization Experiments at the Pore Scale." Groundwater and Subsurface Remediation, H. Kobus. B. Barczewski. and H.-P. Koschizky. Eds.. Springer Verlag. pp. 89-98. 1996.

d) Talks at scientific meetings (presenter underlined if not J.L.Wilsan)

|DOE/ER/60829-04

DOE/ER/60829-02

DOE/ER/60829-05

DOEFER/60829-07

DOE/ER/60829-09

DOE/ER/60829-01

DOE/ER/61484-06

"The Role of the Clay Fraction in Capillary Trapping of Organic Liquids in Soils." (with R. Mace) Fall AGU Meeting. San Francisco.California. December. 1989.

"Flow Visualization Experiments at New Mexico Tech." DOE Subsurfacc Scicnce Program Workshop. Lawrence Berkeley Lahoratory. December, 1989. 
"Small Scale Laboratory Sudies." DOE Subsurface Science Program Annual Meeting. Germantown Maryland. March. 1990.

"Quantitative Comparison of Computational and Experimental Methods for Three Phase Immiscible Transport." (with W.Soll and M. Celia) Conference on Subsuface Contaminarion by Immixcible Fluids.C.algary. Albera, Canada, April, 1990.

"Pore Scale Behavior of Spreading and Non .spreading Organic Liquids in the Vadose Zone." Conference on Subsurface Concamination by Immiscible Eluids. Calgary. Alberta. Canada. April. 1990.

"Visualization of Flow and Transport in Heterogeneous Media." ith Canadian/American Conference on Hydrogeology . Parameter Idencification and Estimation for Aquifer and Reservoir Characlerization. LAHS, Calgary. Alberta. Cansda. September. 1990.

"Visualization of Colloid Transpont During Single and Two-Fluid Phase Flow in Porous Media." (with J. Wan) Manipularion of Groundwater Colloids for Environmental Restoration. Manteo. North Carolina, October. 1990.

"Clay and Immiccible Organics: How Clay and the Physical Activity of an Immiscible Organic Pbase Can Lead to Greater Capillary Trapping of the Organic Phase." (with R. Mace) 65th Colloid and Surface Science Sympo: sium. Norman. Oklahoma. June. 1991.

"Colloid Transport and the Gas-Water Interface in Porous Media" (with L.Wan) 65th Colloid and Surace Science Symposium. Norman, Oklahoma. June, 1991.

"Small Scale Laboratory Studies of Multiphase Flow and Colloid Transport." Multiphase Flow Suborograrm Meetine. Subsurface Science Program. Dept. of Energy. Socorro, New Mexico. Fehruary, 1992.

"The Role of the Gas-Water Interface on Particle Transport through Porous Media" (wich L Wad AGU Hydrology Days. Fort Collins. Colorado. April 1992.

"Scaling Capillary Pressure-Saturation Curves for Hydropillic and Surface Treared Glass Bead Packs" (with P. Burck. R.S. Bowman. and N.R.Morrow) AGU Hydrology Days Meeting. Fort Collins. Colorado. April. 1992.

"Visualization of Colloid Movement in Porous Media" (with J. Wan) Spring AGU Meening. Montreal. Canada. May. 1992.

"Visualization of Groind Waler Flow and Transport Through a Microscope." Keynote Address, Arnual Meeting. Association of Ground Water Scientists and Engineers. Las Vegas, Nevada, October. 1992.

"The Influence on Wettability on Scaling the Capillary Pressure-Sanuration Relationship" (wich P. Burck. R.S. Bowman. and N.R.Morrow) Fall AGU Meeting. San Francisco. California. December, 1992. DOF/ ER/61484-01

"The Role of the Gas-Water Interface on Transport of Colloids and Bacteria in Porous Media," (with J. Wan) Fall AGU Meeting. San Francisco. California. December. 1992.

"Blobs. Calloids and Bugs," Muliphase Flow Subprogram Mecting. DOE Subsurface Science Program. Dept. of Energy. Pacific Northwest Laboratory. Hanford. Washington. March. 1993.

"The Role of the Gas-Water Interface on Transport of Colloids in Porous Media." (with J. Wan). Department of Energy Colloid Transport Meeting. Santc Fe. New Mexico. May. 1993.

"Microscopy of Micro-Organism Transport in an Artificial Porous Matrix." (with J. Wan and T. Nowicki) Spring AGU Meeting, Baltimore. Maryland. May. 1993.

"Blobs. Bugs. and Colloids." Summer Technology Development Series. Waste-Management Education and Research Consortium (WERC). Albuquerque. New Mexico. August 4, 1993. (Telecast nationally via cabe/satellite)

"Role of the Gas-Water Interface on Transport of Colloids in Porous Media," (with I. Wan) 206th American Chemical Society National Meeting. Chicago. Dlinoirs. August. 1993 (On of Five Best Srudent Papers in ACS Environmental Chemistry Division).

"Role of the Gas-Water Interface on Transport of Colloids in Porous Media." (with L Wan) 206ih American Chemical Saciety National Meeting. (hicago. Mllinoirs. Augusc. 1993.

"The Effects of the Gas-Water Interface on Transport of Microorganisms Through Unsaturated Porous Media." (wich J. Wan and 'T.L.Kieft) 1993 Int't Sym. on Subsurface Microbiology. Bath. United Kingdom. September. 1993. 
"Blobs. Bugs and Colloids: Microscopy of Porous Media." Keynote Address, U.S. Geological Survey Toxic Substances Hydrolosy Technical Meeting. Colorado Springs Colorado. September. 1993.

"Recent Visualization and Column Studies of Colloids and Bacteria in Porous Media." 1993 Fred Holmsley Moore Distinguished Locture. Deparment of Environmental Sciences. University of Virginia. Charlottsville. Vurginia. Seprember 30, 1993.

"Visualization of Flow and Transport at the Pore Level." Keyoote Address. IAIIR Int't Sym. on Transporland Beactive Processes in Aquifers. ETH. Zurich. Swizerland. April, 1994.

"Progress in the Use of Micromodels to Investigate Multiphase Fluid Flow." IASONMcetine La Jolla, California. June 22. 1994.

"Processes Controlling the Distribution of Oil, Air and Water." Inminsic Bioremediation of Groundwater. U.S. Environmental Protection Agency, Denver, Colorado. September. 1994.

"Estimation of Bacterial Hydrophobicity from Contact Angle Measurements: an Improved Method," (with M. Elinsch) Eall AGU Meting. San Francisco. California. December, 1994: abstract only. EOS. 75(44), $245,1994$.

"Complications When Multiphase Flow Encounters Mobile Colloids." Dunwalke Workshor on Elow in Po rous Media. Princeton University. Dunwalke Estate, New Jersey. April 28-30. 1995.

"Experiments at the Pore Scale," VEGAS Symposium. University of Suitgart. Stungart, Germany. September 26.27. 1995.

"A New Assay for Microbiological Hydrophobicity." CSIRO. Perth. Australia, May 20. 1997.

"Relationships Between Gcochemical and Physical Heterogeneities." (with R.W. Smith. T.L. McLing. A.L. Schafer. and D.J. Swift) , AGU Spring Meering. Baltimore, June. 1997.

"Visualisation of Groundwater Flow and Transpon Through a Microscope." Inst. of Engineers and University of Melbourne. Melbourne. Australia. 9 July. 1997.

"Sedimentary Facies as a Guide to Hydrologic Properuies in an Experimental Aquifer of Shallow Marine Origin: Virginia's Eastern Shore Peninsula." (with D. Swift. B. Parsons. A. Mueller. R.G. Taylor. R. Holt. R. Smith. A. Schaffer. T. McLing) Spring AGU Meeting, Baltimore. Maryland. May, 1996 ; abstract only. EQS. $77(17)$. . \$100. 1996.

"Laboratory Derived Air Mini-Permeameter Comections for In-sin Sanuration in Unconsolidaned Sand and Their Influence on Estimated Intrinsic Permeability Spatial Variability at Oyster. Va.." (with R. Taylor Eall AGU Meeting. San Francisco. California, December. 1996.

Some of these presentacions evolved into one of the book or procceedings papers listed under item $b$. The AGU talks were published only as abstracts:

Wilson. J.L. and R. Mace. 1989. The Role of the Clay Fraction in Capillary Trapping of Organic Liquids in Soils. EOS. Vol. 70. No. 27. p. 189.

Soll.W.E. and M. Celia, 1991. A Physically Based Model for Three Fiuid Capillary Pressure -.. Saturation Relacionsbips. EOS. Vol. 72. No. 27. p. 126.

Wan. J. and JL. Wilson. 1992. Visualization of Colloid Movement in Porous Media. Experimears on Transport of Colloids During Gas and Aqueous Fluid Flow in Porous Media, EOS. Vol. 73. No. 14. p. 115.

Wan. J. and J.L. Wilson. 1992. The Role of the Gas-Water Interface on Transport of Colloids and Bacteria in Porous Media, EOS. Vol. 73. No. 27, p. 162.

Burck. P., J.L. Wilson. R.S.Bowman, and N.R.Morrow. 1992, The Influence of Wcttability on Scaling the Capillary Pressure-Saturation Relationship: EOS. Vol. 73, No. 27. p. 164.

Flinsch. M. and J.L. Wilson. 1994, Estimation of Bacierial Hydrophobicity from Contact Angle Measurements: an Improved Method, EOS. 75(44), 245.

Taylor, R and J.L. Wilson, 1996. Laboratory Derived Air Mini-Perneameter Corrextions for In-situ Saturation in Unconsolidaced Sand and Their Influence on Estimated Intrinsic Permeability Spacial Variability at Oyster. Va., EOS. 77(46). F207.

e) Other lectures given to scientific audiences

"Pore Scale Studies of the Behavior of Multi-phase Fluids in Porous and Fractured Media." invited seminar presented at the Waterloo Centre for Groundwater Research. University of Waterloo. Waterloo. Ontario. Canada. July. 1990. 
sep-1i-98 05:24P V.P. for Admin. \& Finance (505)835-5659

"Small Scale Laboratory Studies of Flow and Transport Phenomena in Pores and Fractures." invited talk, Peer Review Mecting. Department of Energy. Washington. D.C.. March. 1991.

"Multiphase Flow and Particle Transport." invited seminar presented to the Department Cheraical and Nuclear Eugineering. Univ. of New Mexico. Albuquerquc. N.M.. March. 1991.

"Pore Scale Visualization of Flow and Particle Transpon." invited seminar presented to the Department Chemical and Nuclear Engineering. Univ. of New Mexico. Albuquerque. N.M. October, 1991.

"Groundwater Flow and Transport through a Microscope," invited seminar presented to the Departments of Civil. Mechanical. and Chemical Engineering. Univ. of California. Berkeley. Ca. December. 1991.

1992 Darcy Lecture on "Visualization of Ground Water Flow and Transpon Through a Microscope." sponsored by the Association of Ground Water Scientists and Engineers. given by invitation only at the following locacions:

New Mexico State University. Las Cruses. New Mexico, February 10, 1992

University of Califormia. Santa Cruz. California, March 3. 1992

Stanford University, Palo Alto. California, March 4, 1992

University of Colorado. Boulder. Colorado. March 13. 1992

Utah State University. Logan. Utah. April 3. 1992

University of Nevada. Reno, Nevada. April 10. 1992

University of Kansas. Lawrence. Kansas. April 15. 1992

University of Dlinois. Champaign. Hinois, April 17. 1992

Arizona State University. Tempe. Arizona, April 27. 1992

University of Arizona. Tucson. Arizona. April 29. 1992

Université Laval. Quebec City. Quebec. May 8. 1992

University of Ottawa. Otcawa. Otatario. May 11, 1992

University of Oklahoma. Norman. OkJahoma. September 9.1992

University of Texas. Austin. Texas. September 11.1992

University of New Hampshire. Durham. New Hampshire. September 18. 1992

Massachusetts Institute of Technology. Cambridge. Massachusetts September 21. 1992

University of Connecticut. Storrs. Conneclicut. September 23. 1992

Princeton University. Princeton. New Jerscy. September 25. 1992

Drexel University. Philadelphia. Pennsylvania. September 28. 1992

University of North Carolina. Chapel Hill, North Carolina. October 27. 1992

University of Florida. Gainesville. Florida. October 28. 1992

Georgia Insticute of Technology. Atlanta. Georgia, October 30.1992

Michigan Techoological University. Houghton. Michigan. November 16. 1992

University of Wisconsin. Madison. Wisconsin, November 18. 1992

United States Geological Survey, National HQ. Reston. Virginia, November 20, 1992

University of Califormia. Davis. California. December 2, 1992

University of California. Berkeley. California. December 2, 1992

New Mexico Institute of Mining and Technology. February 1. 1993

"Blobs, Bugs. and Colloids," Summer Technology Development Series. Waste-Management Education and Research Consortium (WERC). Albuquerque. New Mexico. August 4, 1993. (Telecast nationally via cabe/satellite)

"Visualization of Groundwater Transport at the Pore Scale." Departuent of Civil and Environmental Engincering. Vanderbuilt University. Nashville. Tennessee. February 28, 1994,

"Visunlization of Groundwater Flow and Transport Through a Microscope." Deparment of Civil and Environmental Engincering, Washington University, Si. Louis, Missouri, October 24. 1994. 
"Visualization and Column Studies of Colloids and Bacteria in Porous Media." Invited Seminar, School of Civil Engineering. Georgia Institute of Technology. Atlanta. Georgia. January 27, 1995.

"Groundwater Hydrology: Earth Science at the Intersection of Mathematics. Physics, Chernistry and Biology," New Mexico Mathematics and Science Teachers Symposium. New Mcxico Tech. Socomo. New Mexico. March 3. 1995.

"Visualization and Column Studies of Colloids and Bacteria in Unsaturated Porous Media." Invited Seminar. Deparment of Chemical and Environmental Engineering, University of Arizona. Tucson. Arizona. January 23. 1996.

"A New Assay for Microbiological Hydrophobicity," CSIRO، Perth. Australia. May 20. 1997.

"Visualization of Groundwater Flow and Transport Through a Microscope." Int'I Assoc. of Hydrogeologists. Perth. Auscralia. June, 1997

"Visualization of Groundwater Flow and Transport Through a Microscope," 1997 Lecture Tour. sponsored by the CSRO. given by invitation at the following locations:

"Visualization and Column Studies of Colloids and Bacteria in Unsafurated Porous Media." CSRRO. Perth. Australia. June 3,1997. 